Research Article

\title{
Mechanical Properties of New Composite Wood-Plastic Formworks with Aluminum Alloy Frame
}

\author{
Kairong Shi, ${ }^{1,2}$ Jiebin Xu, ${ }^{1}$ Zhengrong Jiang $\mathbb{D}^{1,2}{ }^{1,2}$ unfeng Lv, ${ }^{1}$ and Yonghui Lu ${ }^{1}$ \\ ${ }^{1}$ School of Civil Engineering and Transportation, South China University of Technology, Guangzhou 510641, China \\ ${ }^{2}$ State Key Laboratory of Subtropical Building Science, South China University of Technology, Guangzhou 510641, China
}

Correspondence should be addressed to Zhengrong Jiang; 63287677@qq.com

Received 24 July 2020; Revised 11 November 2020; Accepted 20 November 2020; Published 7 December 2020

Academic Editor: Michael Yam

Copyright (c) 2020 Kairong Shi et al. This is an open access article distributed under the Creative Commons Attribution License, which permits unrestricted use, distribution, and reproduction in any medium, provided the original work is properly cited.

Formwork engineering plays a crucial role in cost, efficiency, quality, and schedule in civil engineering. Currently, wood-plastic formwork, which has favorable mechanical properties such as wood and excellent stability, formability, ease of demolding, and time-saving as plastic, is earning its increasing reputation in construction. This work focuses on mechanical properties of two types of new composite wood-plastic formworks with aluminum alloy frame used for construction, that is, single-span simply supported and three-span continuous formworks. Experimental investigation shows that the two types of wood-plastic formworks demonstrate favorable performance, and the deflections and stresses are within the allowable range, thereby satisfying the structural bearing requirements. Numerical analyses confirm that the results of the refined and general finite element models are consistent with the experimental results, but the former has a higher accuracy. When the requirement of accuracy is not too strict, the general model is preferred, given the modeling convenience and high efficiency. On the basis of experimental and numerical investigations, practical simplified formulas are proposed to facilitate rapid calculation and evaluation considering transverse deflection and inconsistency of two materials. Therefore, the results in this work can provide a theoretical basis for developing and applying the new formworks.

\section{Introduction}

Cast-in-place reinforced concrete structures play a crucial role in civil engineering and comprise a large part of an infrastructure. Many experiments and simulation analyses are conducted to ensure that the mechanical properties of concrete are within limits considering mix design and curing condition [1-4]. Concrete cannot be cast without formwork, which is the foundation for concrete structure forming. Formwork engineering is an important component and the core process of concrete structure construction. Various formworks result in different costs, efficiencies, qualities, and schedules [5-7].

Several formworks are commonly used in construction. The first one is wooden formwork, which is gradually being replaced by plywood formwork given a small dimension, poor bearing capacity, large density, and poor water resistance of wooden formwork. The second one is steel formwork. In comparison with wooden formworks, steel formworks raise the rate of use and reduce water pressure. However, the large density of steel complicates transportation and installation. Moreover, steel is easily corroded without careful maintenance. The third one is aluminum alloy formwork, which has a lighter weight and higher corrosion resistance than a steel formwork. However, its Young's module is only approximately one-third of the steel template, thus leading to poor behavior in deflection control in formworks. The last one is plastic formwork. In contrast to traditional formworks, plastic formworks exhibit certain unique characteristics. Plastic formworks are easy to demold given the smooth surface and its considerable water resistance capacity. In terms of malleability, plastic formworks are easy to process, manufacture, and recycle. However, plastic formworks are prone to aging and warping, and the white waste formed by plastic formworks causes serious environmental pollution. In this work, a new composite 
wood-plastic formwork is introduced. It is a new polymer formwork, which comprises wood and plastic in a certain manner. It has favorable mechanical properties such as wood and excellent stability, formability, advantage of reuse, and high efficiency of demolding as plastic.

Several research works have been conducted to assist in selecting appropriate formwork systems. Tam et al. [8] and Hanna and Senouci [9] developed neural network models for selecting vertical and horizontal formwork systems, respectively. Nikhil and Patil [10] used fuzzy logic based on comparative analysis to automate the formwork knowledge base, which aids in formwork selection. Martinez et al. [11] developed the choosing by advantages decision-making method to lead decision makers in selecting the suitable formwork. Other research works have focused on the mechanical analyses of formworks with different materials. Meng et al. [12] presented experimental and mechanical studies on flexural behaviors of fiber-reinforced polymer fabric-reinforced ultrahigh-performance concrete panels. Carrillo et al. [13] used finite element (FE) software to assess the mechanical performance of different sizes of steel formwork. Gallego et al. [14] applied the ANSYS FE program to simulate wooden and steel formworks in calculating the lateral pressures of a complex-shaped formwork. Wang et al. [15] conducted numerous comparative analyses of bearing capacity and stability for plywood formwork. Wang et al. [16] investigated the effect of internal curing with presoaked lightweight aggregate and engineered cementitious composite permanent formwork on moisture distribution in a drying environment. However, an analysis of references shows that few researchers have concentrated on the mechanical analysis of the new composite wood-plastic formwork.

The use of concrete as a structural material in civil engineering requires adopting formworks, which must remain in place until the concrete setting is completed [17]. Therefore, a formwork is an important tool for constructing concrete structures, especially for cast-in-place concrete. This work presents the results of experimental and numerical simulations of the two types of new composite wood-plastic formworks (i.e., single-span simply supported and three-span continuous formworks). Single-span simply supported formwork only can be used in concrete slab less than $6000 \mathrm{~mm}$. Here, the two types of formworks perform well and can, therefore, be used.

\section{Geometric Parameters and Material Properties}

2.1. Geometric Parameters. The structure of the proposed new formworks consists of two parts, namely, wood-plastic template (surface slab) and aluminum alloy frame. Rivets are used to tie a template and a frame together. This work targets two types of specimens, namely, Type I (single-span simply supported formwork; Figure 1) and Type II (three-span continuous formwork; Figure 2). The dimension of Type I is $1500 \mathrm{~mm} \times 600 \mathrm{~mm} \times 65 \mathrm{~mm}$, whereas that of Type II is $2700 \mathrm{~mm} \times 600 \mathrm{~mm} \times 65 \mathrm{~mm}$. The template thickness of both specimens is $10 \mathrm{~mm}$.
2.2. Material Properties. The template of the formwork is made of a new kind of environmentally friendly composite material called wood-plastic. All other members in the formwork are made of 6061-T6 aluminum alloy in addition to steel rivets. The detailed material data are listed in Table 1.

\section{Experimental Investigation}

3.1. General Test and Loading Scheme. To investigate the mechanical properties of formworks, three specimens are fabricated for each type of formwork. Table 2 summarizes the general information of the formwork experiments. Steel blocks $(2.5 \mathrm{~kg})$ are used to simulate the uniform load. The measurement contains the following main parts:

(1) Deflection in the middle of the span

(2) Stress and strain in the middle of the span and support

\subsection{Single-Span Simply Supported Formwork}

\subsubsection{Arrangement of the Measuring Points}

(1) Arrangement of the Measuring Point of Deflection. Figure 3 illustrates five measuring points (A-E) to monitor the vertical deflection in the middle of the span.

(2) Arrangement of the Measuring Point of Strain. Figure 4 depicts four measuring points (1-4) placed on the interesting points of the frame to monitor the strain. The measuring points are separately distributed in the middle of four longitudinal beams of the frame.

3.2.2. Loading Process. The loading process of the singlespan simply supported formwork is demonstrated as follows: first, the proposed formwork specimens are placed on a special experimental bench. Second, the deflection meters, resistance strain gauges, and other devices are installed. To ensure uniformity of loading with steel blocks, the top surface of the wood-plastic template is covered with a thin layer of fine sand. Then, the steel blocks $(2.5 \mathrm{~kg})$ are applied uniformly on the formwork step by step to achieve a uniform load. The loading region is demonstrated in Figure 5. The strain data are collected in the computer transmitted by strain gauges. The deflection data can be read directly from the meters.

Before the formal experiment, the specimens are preloaded to check whether the specimens are placed stably, and the test instruments are set up correctly, thus ensuring that the experimental devices can work accurately and reduce the test error during the whole experiment. The abovementioned preloading reaches $5 \mathrm{kN}$ and is held for $3 \mathrm{~min}$.

During the formal loading, $2.5 \mathrm{kN} / \mathrm{m}^{2}$ at each step is loaded until it reaches $15 \mathrm{kN} / \mathrm{m}^{2}$ (self-weight of $600 \mathrm{~mm}$ concrete). All data are recorded after loading for more than $30 \mathrm{~s}$. The loading procedure is presented as follows: $0 \longrightarrow 2.5 \mathrm{kN} / \mathrm{m}^{2} \longrightarrow 5 \mathrm{kN} /$ $\mathrm{m}^{2} \longrightarrow 7.5 \mathrm{kN} / \mathrm{m}^{2} \longrightarrow 10 \mathrm{kN} / \mathrm{m}^{2} \longrightarrow 12.5 \mathrm{kN} / \mathrm{m}^{2} \longrightarrow 15 \mathrm{kN} /$ $\mathrm{m}^{2} \longrightarrow 0$. 


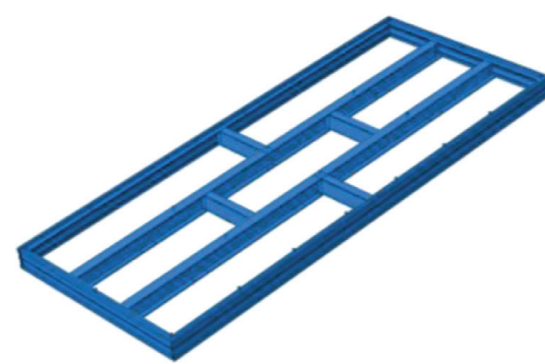

(a)

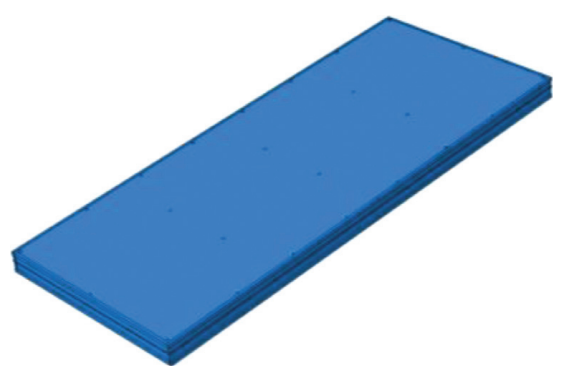

(b)

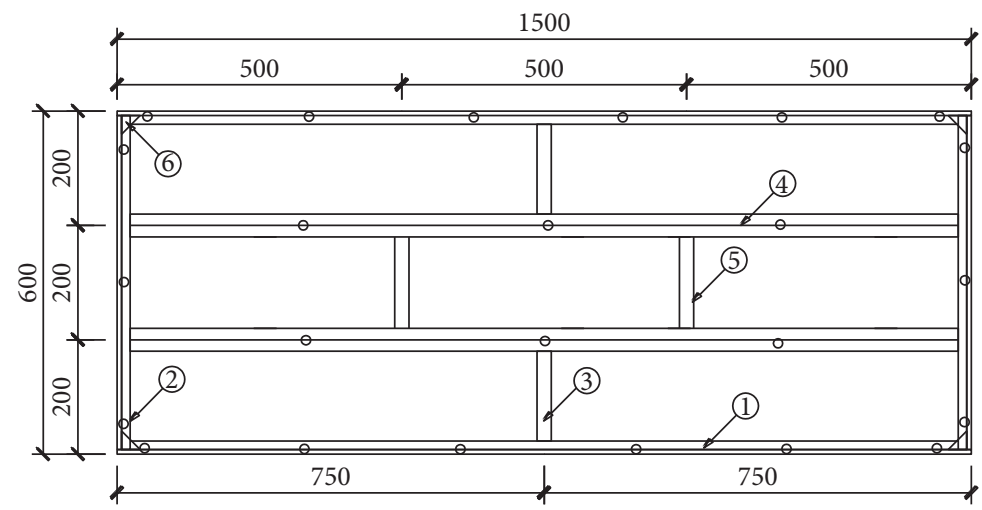

(c)

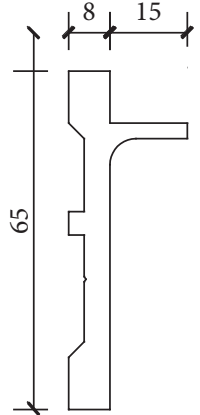

(d)

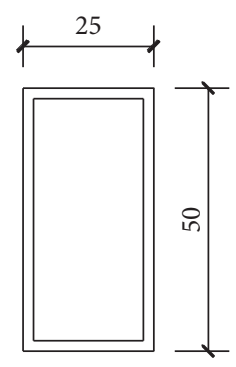

(e)

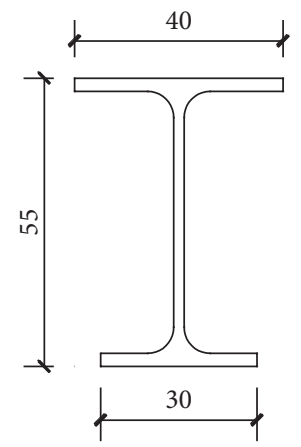

(f)

FIGURE 1: Geometric model of a single-span simply supported formwork (Type I). (a) Model of a frame without a template. (b) Model with a template. (c) Dimensions of the formwork. (d) Sections of (1) and (2). (e) Sections of (3) and (5). (f) Section of (4).

During the actual process of loading step by step, the deformation of the formwork and the corresponding stress and strain increase with the uniform load. The experimental data collected are acceptable, and no apparent abnormality is found. The entire process is completed smoothly. The details of the loading process are exhibited in Figure 6.

3.2.3. Results of the Experiments. Figures 7 and 8 display the average experimental results of deflections and stresses of the formwork specimens, respectively.

The load-deflection curves of the specimens are nearly linear. The largest deflection is located in point $\mathrm{C}$ in the middle of the span and reaches $1.954 \mathrm{~mm}$ when subjected to the load of $15 \mathrm{kN} / \mathrm{m}^{2}$, which is smaller than the allowable value of $2.25 \mathrm{~mm}$ (1/400 of span) [18].

Figure 8 presents that the stress at the critical points increases linearly with the load, and the average value of the maximum tensile stress is approximately $60 \mathrm{~N} / \mathrm{mm}^{2}$, while the average value of the maximum compressive stress is approximately $-30 \mathrm{~N} / \mathrm{mm}^{2}$, which is smaller than the allowable value of $200 \mathrm{~N} / \mathrm{mm}^{2}$ (yield strength).

In addition, during the loading process and after unloading, no apparent damage or bending buckling occurs.

\subsection{Three-Span Continuous Formwork}

\subsubsection{Arrangement of the Measuring Points}

(1) Arrangement of the Measuring Points of Deflection. Figure 9 illustrates the five measuring points (A-E) to monitor the vertical deflection along with the three spans.

(2) Arrangement of the Measuring Points of Strain. Figure 10 depicts the five measuring points (1-5) placed on the interesting points of the frame to monitor the strain. They are 


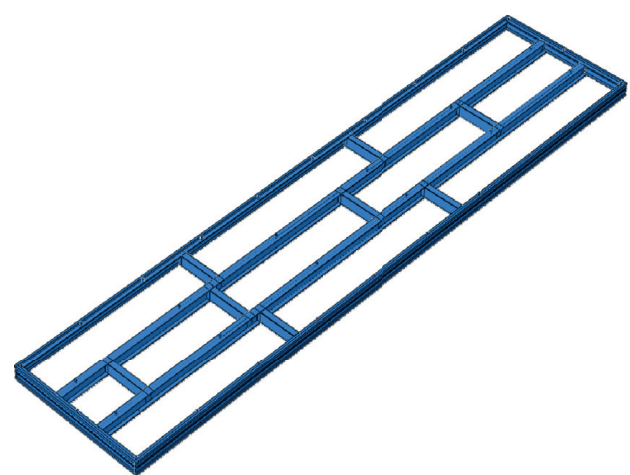

(a)

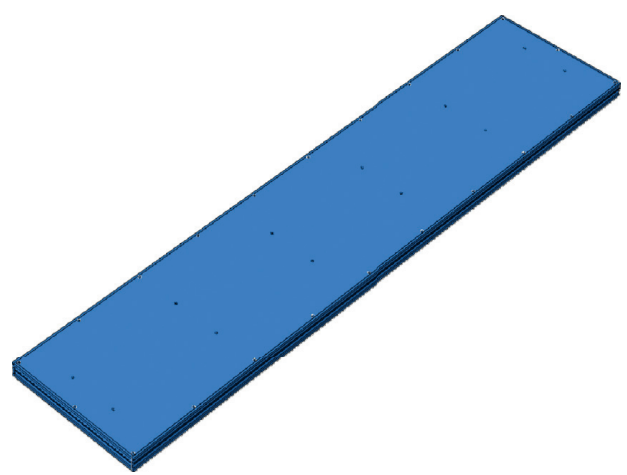

(b)

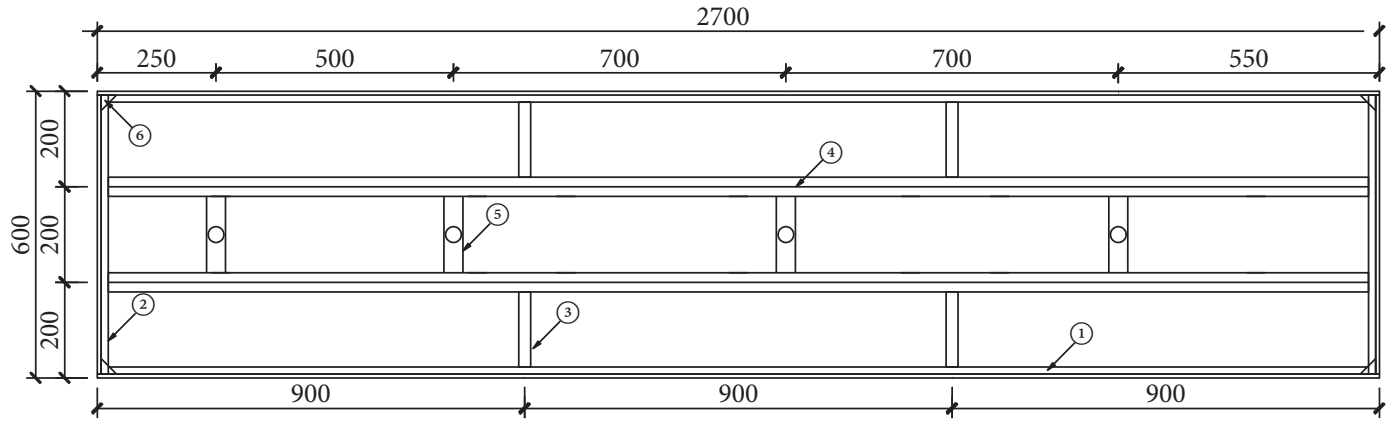

(c)

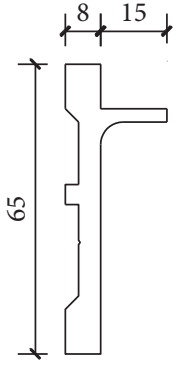

(d)

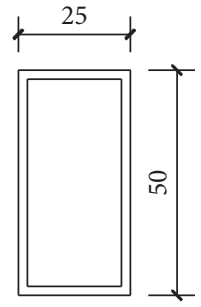

(e)

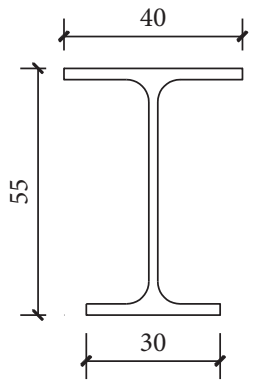

(f)

Figure 2: Geometric model of a three-span continuous formwork (Type II). (a) Model of a frame without a template. (b) Model with a template. (c) Dimensions of the formwork. (d) Sections of (1) and (2). (e) Sections of (3) and (5). (f) Section of (4).

TABLE 1: Material properties of the composite wood-plastic formwork.

\begin{tabular}{lcccc}
\hline Member & Material & Density $\left(\mathrm{kg} / \mathrm{m}^{3}\right)$ & Young's modulus $\left(\mathrm{N} / \mathrm{mm}^{2}\right)$ & Poisson's ratio \\
\hline Template & Wood-plastic & $1.26 \times 10^{3}$ & $3.84 \times 10^{3}$ & - \\
Frame & 6061-T6 aluminum alloy & $2.70 \times 10^{3}$ & $0.70 \times 10^{5}$ & 0.3 \\
Rivet & Steel & $7.85 \times 10^{3}$ & $2.06 \times 10^{5}$ & 0.2 \\
\hline
\end{tabular}

TABLE 2: Loading program of the formwork.

\begin{tabular}{llcccc}
\hline $\begin{array}{l}\text { Specimen } \\
\text { number }\end{array}$ & Dimension of the formwork & Type of support & $\begin{array}{c}\text { Span } \\
(\mathrm{mm})\end{array}$ & $\begin{array}{c}\text { Length of the cantilever } \\
(\mathrm{mm})\end{array}$ & $\begin{array}{c}\text { Maximum test load } \\
\left(\mathrm{kN} / \mathrm{m}^{2}\right)\end{array}$ \\
\hline $1,2,3$ & $1500 \mathrm{~mm} \times 600 \mathrm{~mm} \times 65 \mathrm{~mm}$ & $\begin{array}{c}\text { Single-span simply } \\
\text { supported }\end{array}$ & 900 & 300 & 15 \\
$4,5,6$ & $2700 \mathrm{~mm} \times 600 \mathrm{~mm} \times 65 \mathrm{~mm}$ & $\begin{array}{c}\text { Three-span continuous } \\
\text { Th }\end{array}$ & $750 \times 3$ & 225 & 30 \\
\hline
\end{tabular}




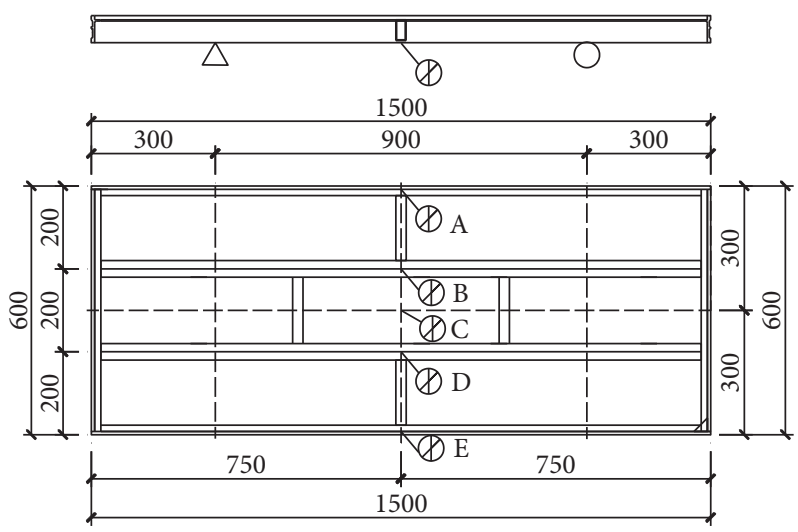

FIgURE 3: Arrangement of the measuring points of deflection in the single-span simply supported formwork.

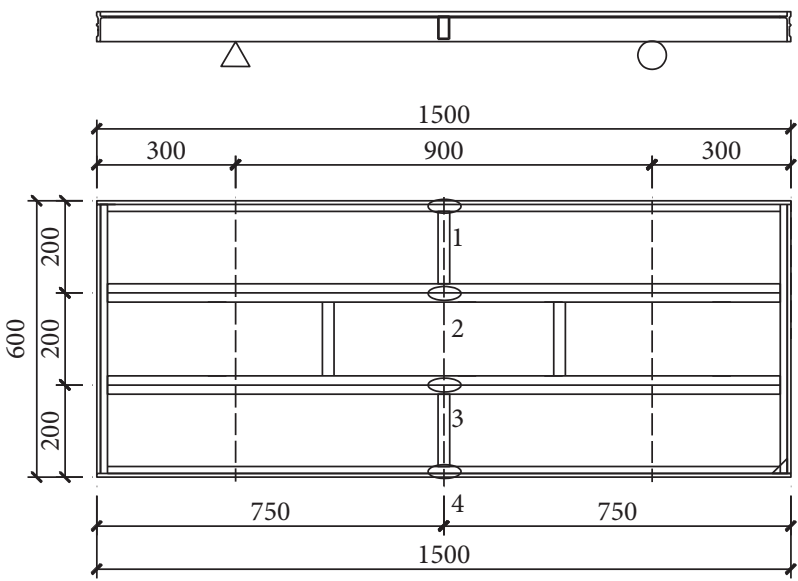

FIGURE 4: Arrangement of the measuring points of strain in the single-span simply supported formwork.

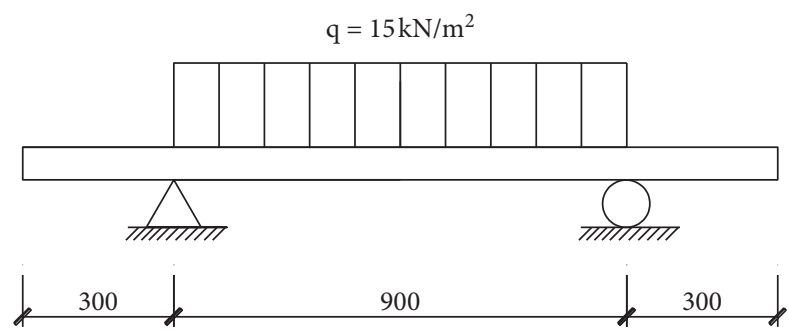

Figure 5: Loading diagram of the simply supported formwork.

separately distributed along a longitudinal beam of the frame.

3.3.2. Loading Process. The loading process of the three-span continuous formwork is similar to that of the single-span simply supported formwork. The loads are applied between the outermost supports (Figure 11). Moreover, the maximum value of preloading reaches $10 \mathrm{kN} / \mathrm{m}^{2}$. For the formal loading, the maximum load reaches $30 \mathrm{kN} / \mathrm{m}^{2}$. The loading procedure is demonstrated as follows: $0 \longrightarrow 5 \mathrm{kN} / \mathrm{m}^{2} \longrightarrow 10 \mathrm{kN} /$ $\mathrm{m}^{2} \longrightarrow 15 \mathrm{kN} / \mathrm{m}^{2} \longrightarrow 20 \mathrm{kN} / \mathrm{m}^{2} \longrightarrow 25 \mathrm{kN} / \mathrm{m}^{2} \longrightarrow 30 \mathrm{kN} /$ $\mathrm{m}^{2} \longrightarrow 0$.
The details of the loading process are exhibited in Figure 12.

3.3.3. Results of the Experiments. Figures 13 and 14 display the average experimental results of deflections and stresses of the formwork specimens, correspondingly.

Similarly, the load-deflection curves of the specimens are nearly linear. Moreover, the results of the three tests are nearly consistent with one another. The largest deflection is located in points $\mathrm{B}$ and $\mathrm{E}$ and reaches approximately $1.336 \mathrm{~mm}$ when subjected to the load of $30 \mathrm{kN} / \mathrm{m}^{2}$, which is smaller than the allowable value of $1.875 \mathrm{~mm}$ (1/400 of span) [18]. 

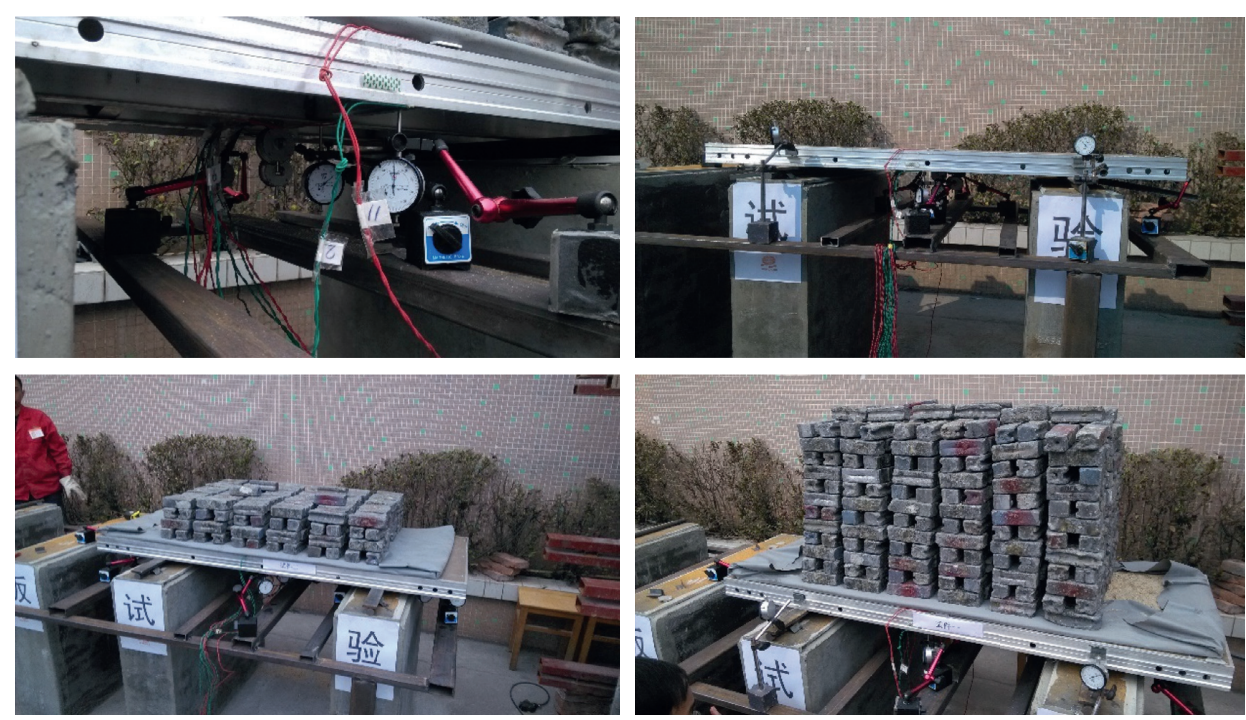

FIGURE 6: Loading process of the single-span simply supported formwork.

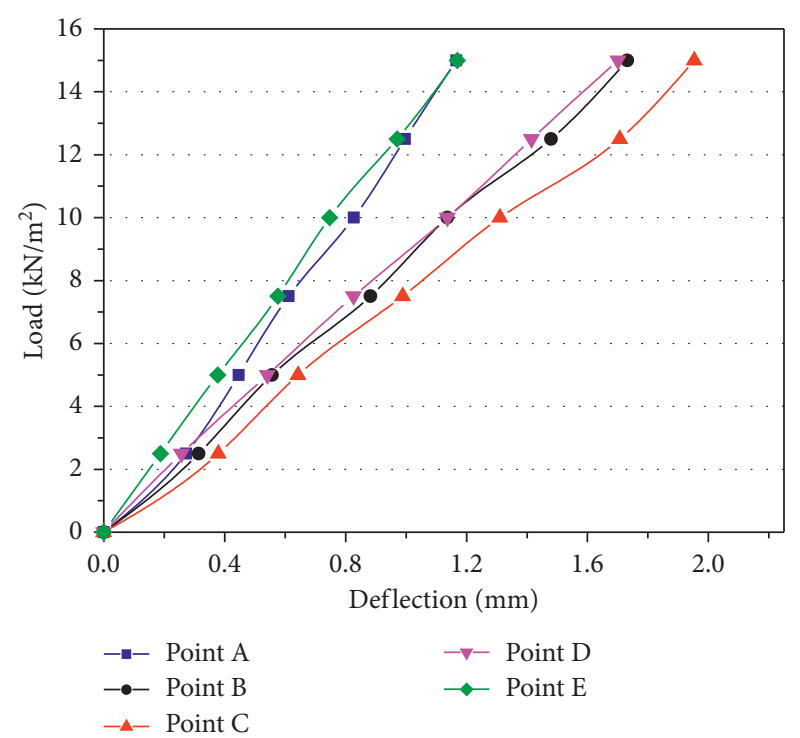

FIgURE 7: Load-deflection curves of the single-span simply supported formwork specimens.

The stress at the critical point increases linearly with the load, and the average value of the maximum tensile stress is approximately $60 \mathrm{~N} / \mathrm{mm}^{2}$, whereas the average value of the maximum compression stress is approximately $-60 \mathrm{~N} / \mathrm{mm}^{2}$, which is much smaller than the allowable value of $200 \mathrm{~N} / \mathrm{mm}^{2}$ (yield strength).

Furthermore, during the loading process and after unloading, no damage, bending, or buckling occurs.

\section{FE Analysis}

\subsection{Methodology of ABAQUS Modeling}

4.1.1. Principle of Finite Element Analysis. The basic step of finite element analysis is to discrete the structure. In

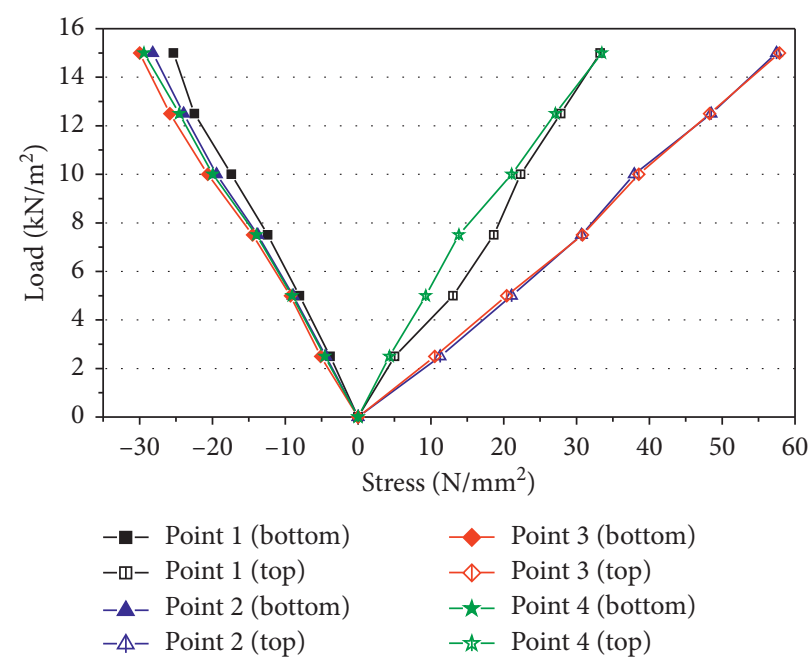

FIGURE 8: Load-stress curves of the single-span simply supported formwork specimens.

ABAQUS, one of the discretization methods used in contact pair is the discretization method of surface-tosurface. In the physical sense, the pressure will transmit between two objects that contact each other at the same time, and there exists shearing force, to be precise, friction to prevent the tangential movement of objects. In the numerical calculation, the contact is extremely discontinuous boundary conditions of nonlinearity; that is, the contact constraints exist only if the contact planes contact each other without gap. If the contact planes separate, the contact constraints will be invalid. Generally, the type of contact can be divided into two kinds. One is surface-based contact while the other is element-based contact. We will discuss surface-based contact, which will be used in the following finite element analysis. According to Figure 15, the discretization of surface-to-surface is that the node on the average region of the slave surface discretizes normally 


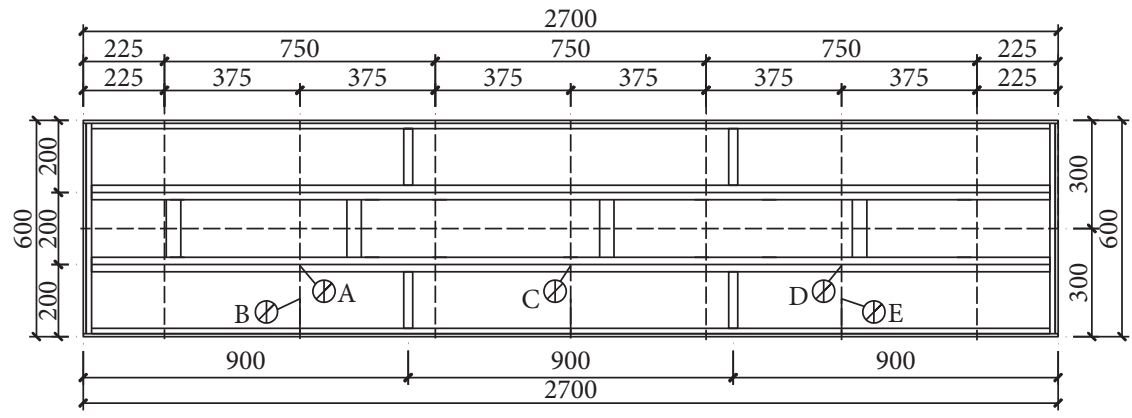

FIgURE 9: Arrangement of the measuring points of deflection on the three-span continuous formwork.

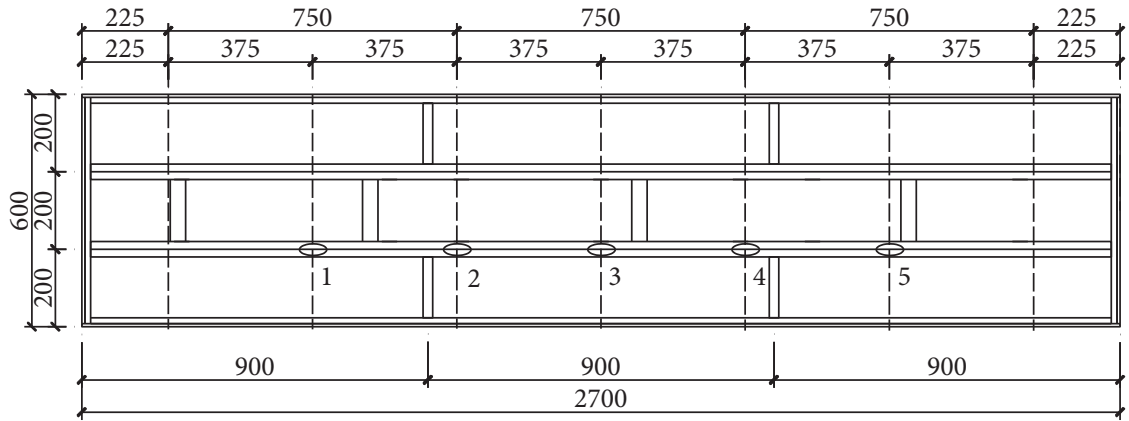

FIgURE 10: Arrangement of the measuring points of strain on the three-span continuous formwork.

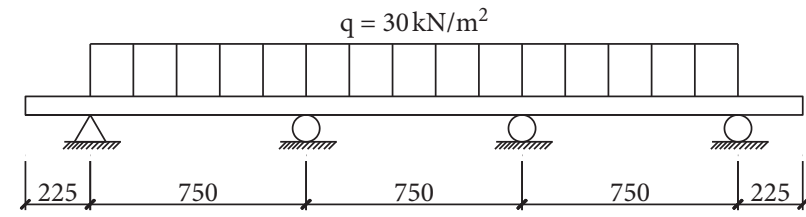

FIGURE 11: Loading diagram of the three continuous supported formworks.
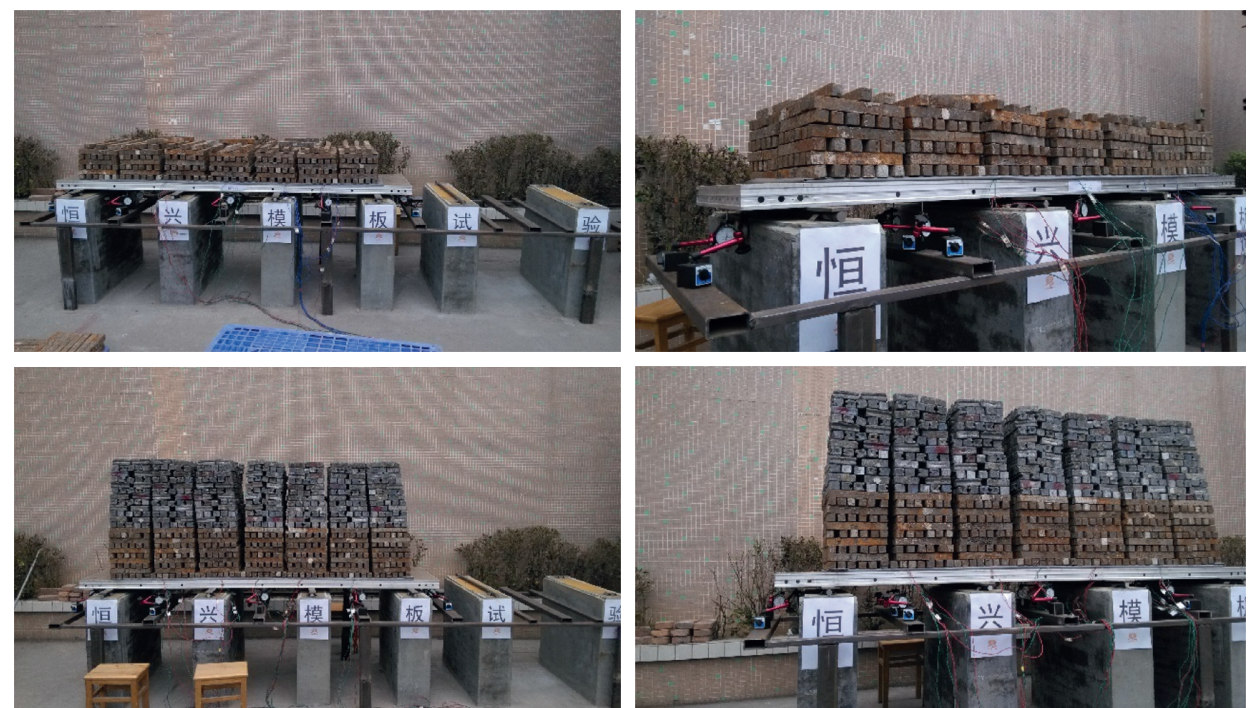

FIGURE 12: Loading process of the three-span continuous formwork. 


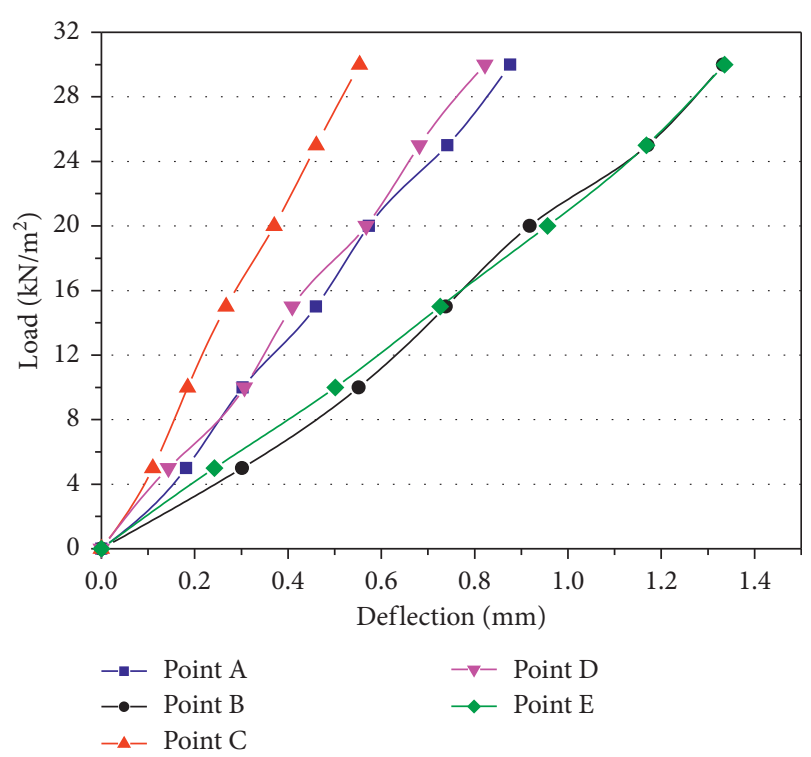

FIGURE 13: Load-deflection curves of the three-span continuous formwork specimens.

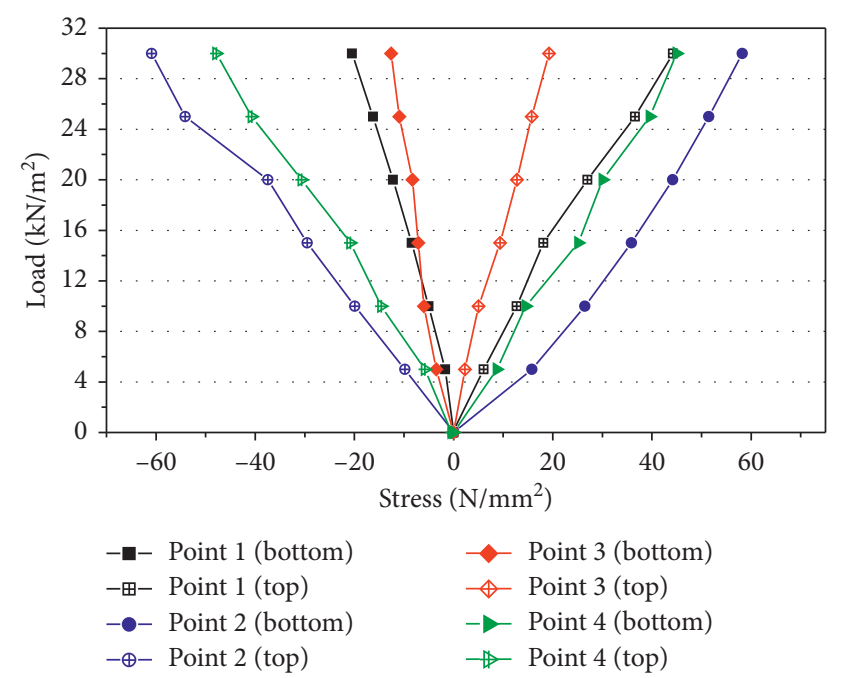

FIgURE 14: Load-stress curves of the three-span continuous formwork specimens.

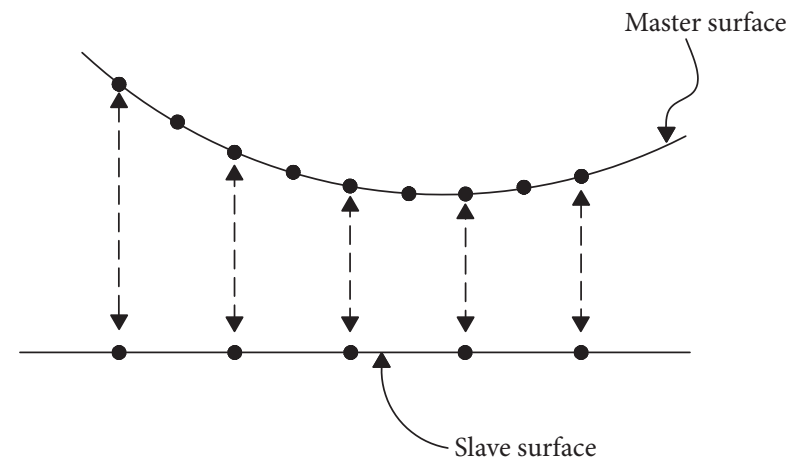

Figure 15: Discretization method of node to the surface. into several continuous small planes. The contact is built on the discrete surface of the slave surface and the master surface adjacent to it. In contact pair, both the slave surface and the master surface are considered as continuous faces, and the contact direction is the normal direction of slave surface. The node from the master surface is not allowed to penetrate the slave surface, but instead, the node of the slave surface can penetrate through the master surface.

As for the tracking method of contact, there are two ways to calculate the relative slip between the contact surfaces: finite sliding and small sliding. As shown in Figure 16, the position of the finite slip node is updated depending on the actual shape of the slave surface, and when the contact constraint is generated, the node 1 of slave surface will be constrained to slip along the path of the master surface, regardless of its direction and deformation. It is used when the instances contacted with each other have large deformation, rotation, and large displacement sliding. The tracking method of the small sliding, assuming that the nodal displacement on the slave surface is relatively small compared with the local curvature of the master surface, updates the location of slave node along with the tangent direction of the master surface, as shown Figure 17.

In addition, the initial geometrical imperfection [19] also has a certain effect on the mechanical properties of the structure, especially for pressure bar and shell structure, but this factor can be ignored for the bending formwork under normal construction load in this paper.

4.1.2. Modeling. In this work, the FE analysis software ABAQUS is used to conduct the numerical simulation of this experiment. Two types of FE models, namely, refined and general, are established.

In the first FE model (refined model), several contact pairs are set, including the relationship between the template and frame, the interaction between the template and rivet, and the interaction between the frame and rivet. The interactions of all the contact pairs are simulated by the contact function in ABAQUS. All contacts are defined to be surfaceto-surface contacts where a "hard contact" is the pressureoverclosure on normal behavior. However, the contact pair between the formwork and support assumes that the friction formulation on tangential behavior is a penalty function, whereas the friction formulation on the tangential behavior of the three other contact pairs is rough, thereby indicating that no slip will occur. Small sliding is used for all the abovementioned contacts. The density of the seeds on frame, template, and supports is all set to $5 \mathrm{~mm}$ with the element type assigned as C3D8R (eight-node linear brick elements with reduced integration). The density of mesh seeds on the rivet is small, given the small dimension, which is $1 \mathrm{~mm}$ (Figure 18). For the boundary condition, pinned supports with a linear displacement of all its nodes impeded in all directions are assumed for the models.

In the second FE model (general model), the rivets are ignored for simplified modeling, but a tie constraint exists between the template and frame, thereby indicating that the 


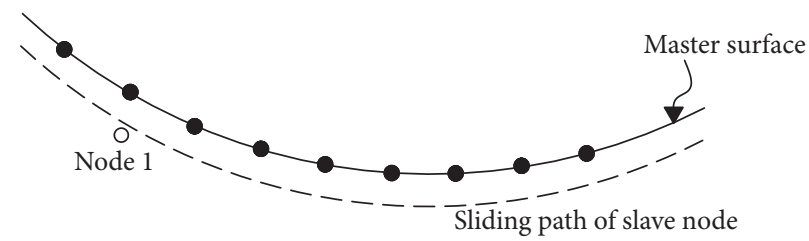

Figure 16: Path of finite sliding.

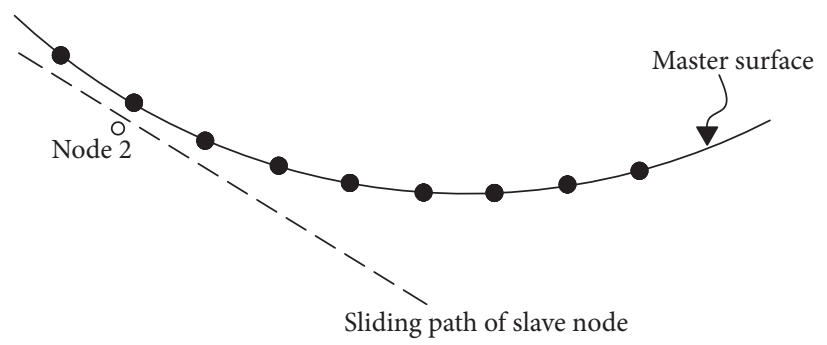

Figure 17: Path of small sliding.

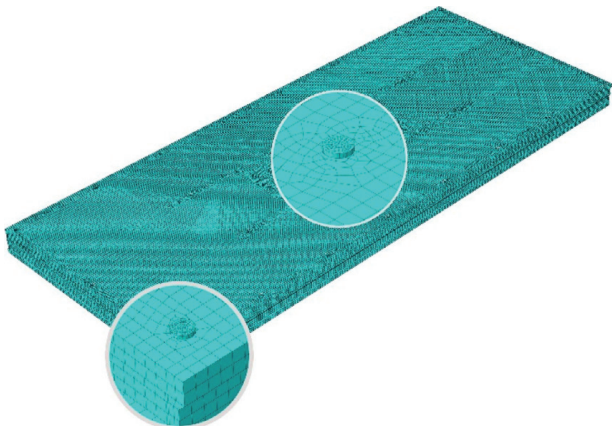

(a)

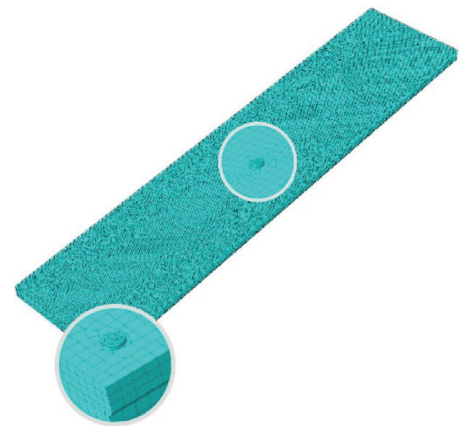

(b)

Figure 18: First FE model (refined models). (a) Single-span simply supported formwork. (b) Three-span continuous formwork.

elements on the contact surface will deform simultaneously. The cross sections of a fringe frame are simplified as rectangular shaped in accordance with the stiffness equivalence principle, and the mesh seed density of all the parts is equal to $10 \mathrm{~mm}$ (Figure 19). Furthermore, the boundary condition is the same as the first model (refined models).

\subsection{Single-Span Simply Supported Formwork}

4.2.1. FE Analysis Result. Figures 20-22 illustrate that two models are consistent with each other in terms of deformation shape and stress distribution.

From the deflection contours of the formwork, under the maximum uniform load with $15 \mathrm{kN} / \mathrm{m}^{2}$, the layout of the maximum deflection of the template is located at the centroid, thus accounting for $2.014 \mathrm{~mm}$ (Figure 20(a)) and $2.009 \mathrm{~mm}$ (Figure 20(b)). In addition, it appears as a concave phenomenon in the middle of the span on the template because two transverse beams are supported under the formwork in the middle of the span, thereby increasing the local stiffness and helping reduce the deflection. Moreover, the deflections at the two cantilevered ends of formwork are positive because the loads are only applied between the supports such that both cantilevered ends will be upturned. The deflection contours of the frame show that the negative extreme value appears in the middle span, whereas the value of the two ends is positive.

The longitudinal stress contour of the frame shows that the maximum longitudinal stress $\left(55\right.$ and $60.07 \mathrm{~N} / \mathrm{mm}^{2}$ in Figures 22(a) and 22(b), respectively) appears in the middle of the span, which is far less than the allowable value $\left(200 \mathrm{~N} / \mathrm{mm}^{2}\right)$. The bending moment is largest at the midpoint of the beam, such that the stress, which is positively correlated with the moment, is also the largest.

4.2.2. Comparison of the FE Analysis and Experimental Results. Figures 23 and 24 depict the comparisons between the FE and experimental results. The prediction of FE is consistent with the corresponding experimental result, thereby denoting that the proposed FE models can reflect the mechanical behavior of formworks well. 


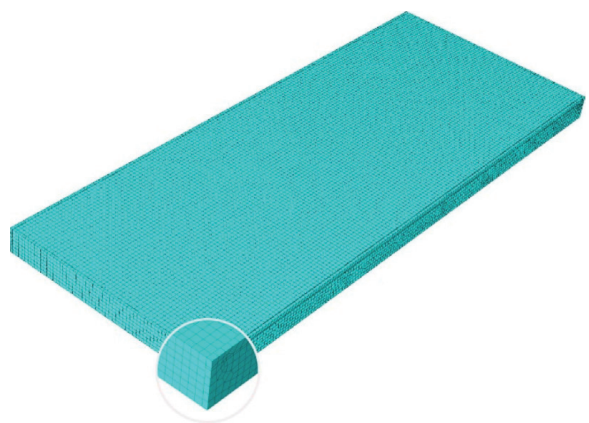

(a)

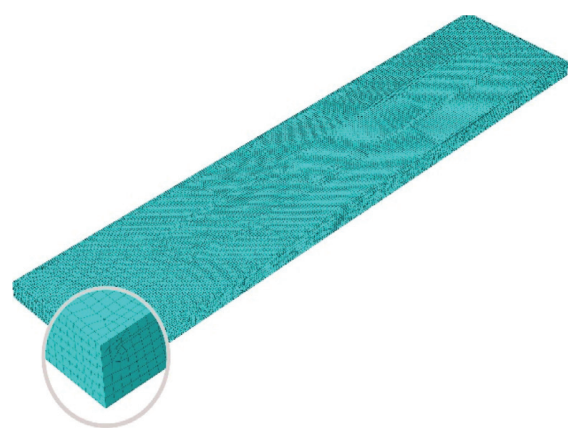

(b)

Figure 19: Second FE model (general models). (a) Single-span simply supported formwork. (b) Three-span continuous formwork.
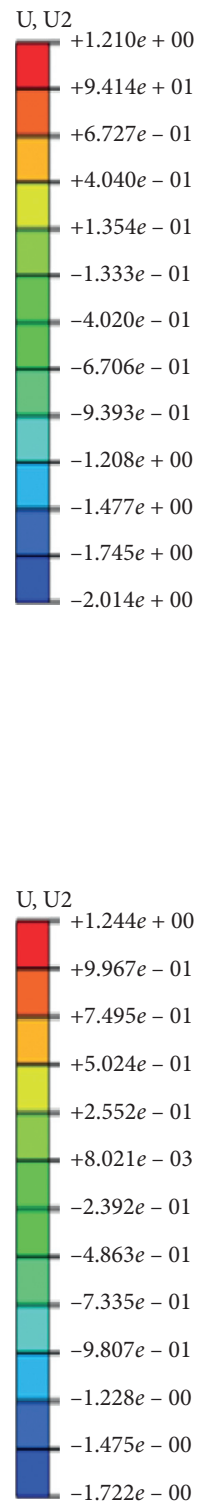

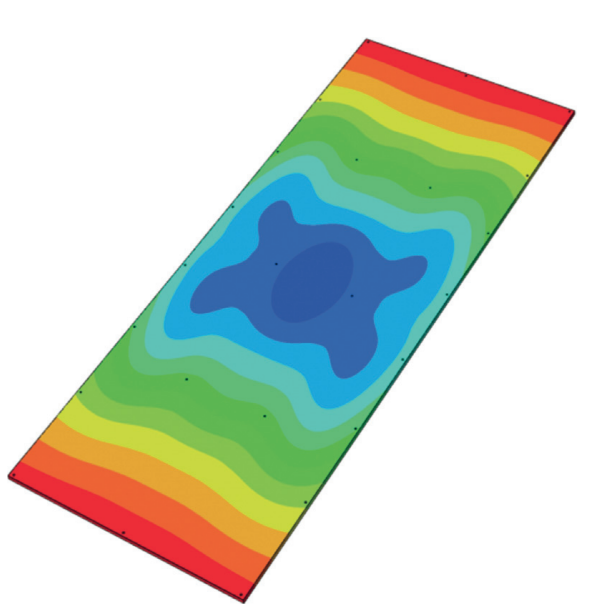

(a)

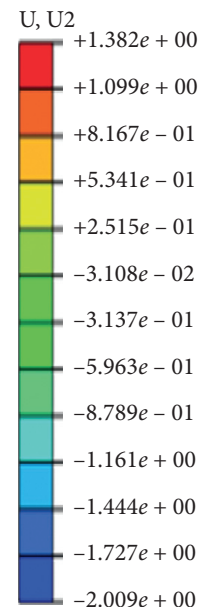

$-2.009 e+00$

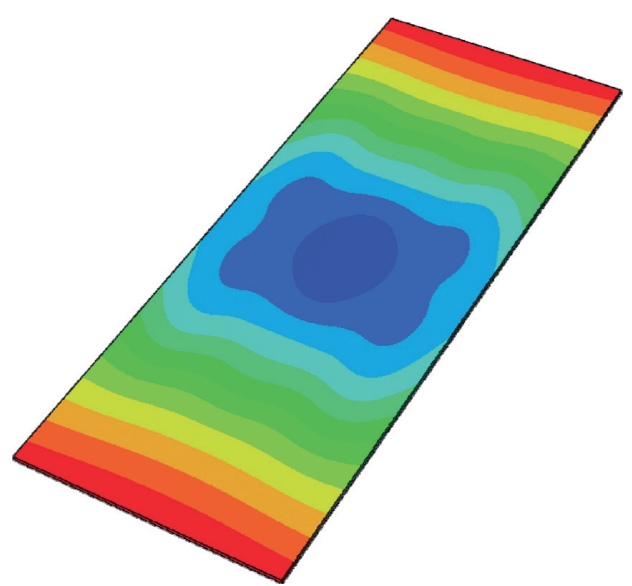

(b)

Figure 20: Deflections of the template (unit: mm). (a) Refined model. (b) General model.

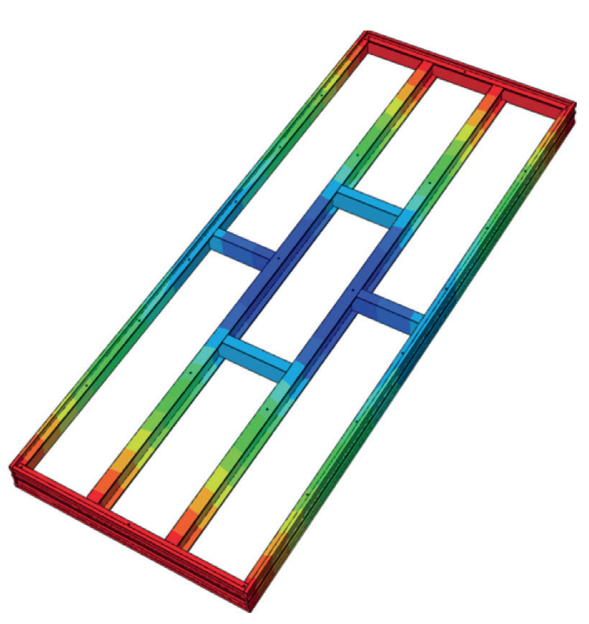

(a)

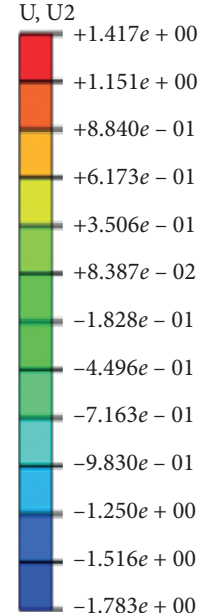

$-1.783 e+00$

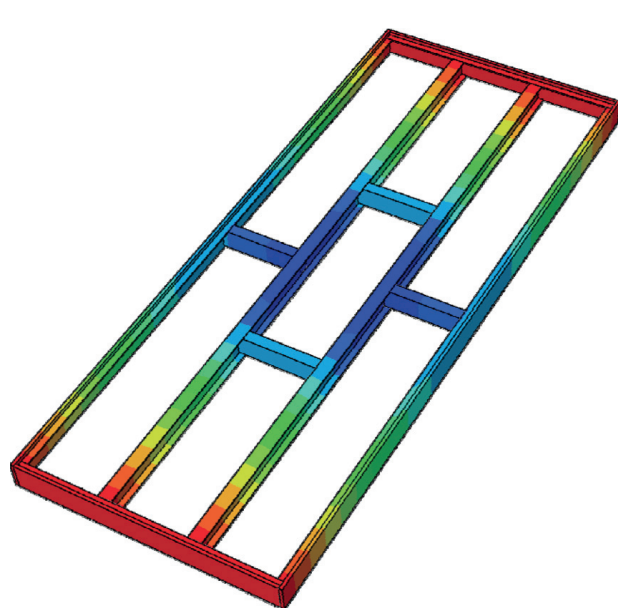

(b)

Figure 21: Deflections of the frame (unit: mm). (a) Refined model. (b) General model. 
S, S33

(Avg: $75 \%)$

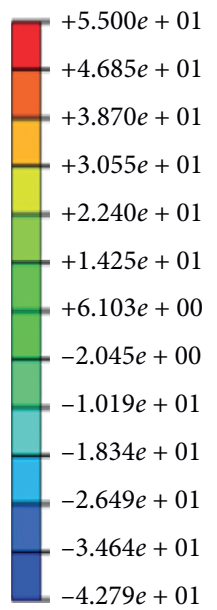

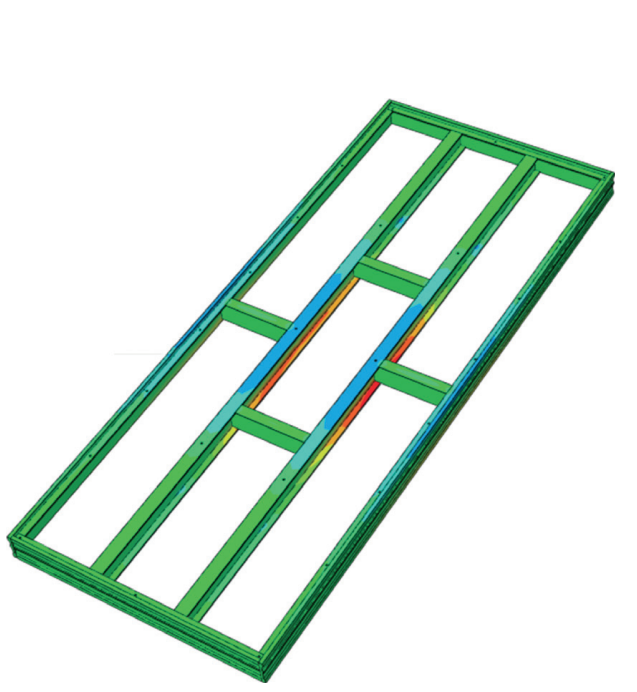

(a)

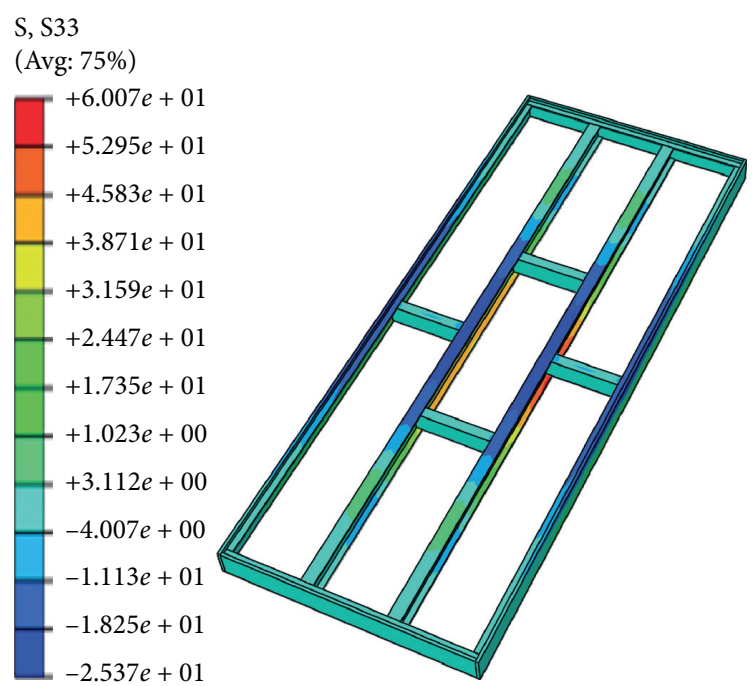

(b)

Figure 22: Longitudinal stresses of the frame (unit: N/mm²). (a) Refined model. (b) General model.

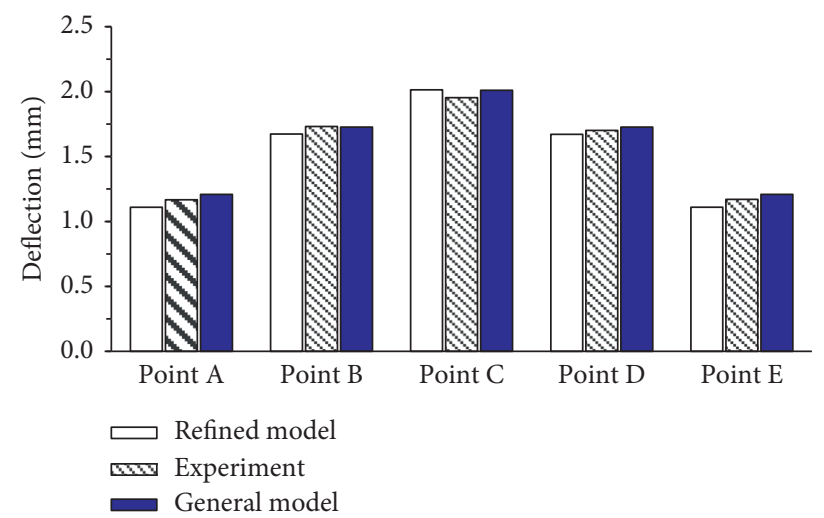

FIgURE 23: Comparison of the deflections between the experiment and FE models.

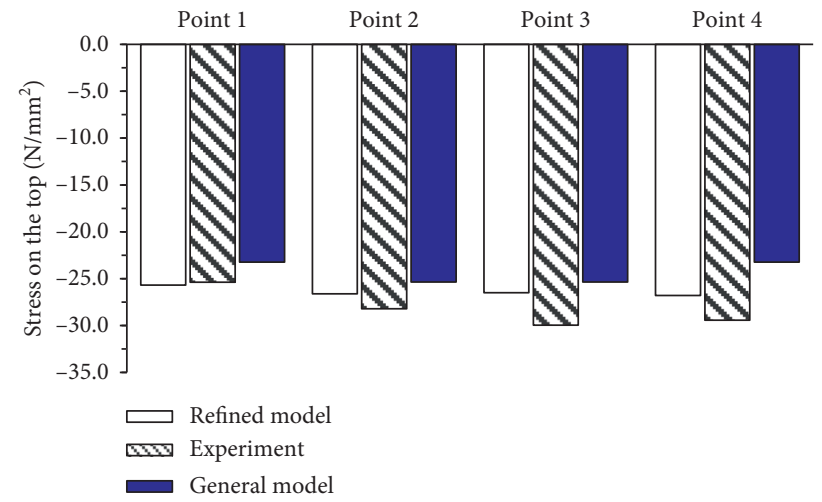

(a)

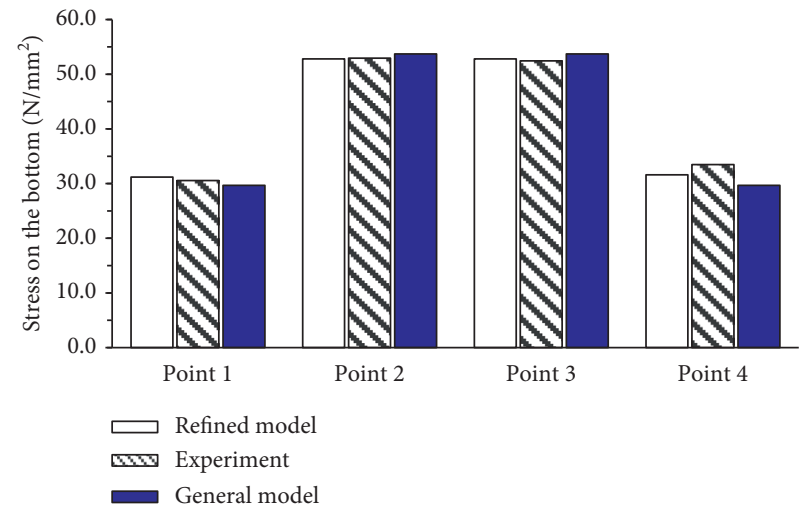

(b)

Figure 24: Comparison of the stresses between the experiment and FE models. (a) Top surface. (b) Bottom surface. 
TABle 3: Comparison of the deflections between the experiment and FE models.

\begin{tabular}{|c|c|c|c|c|c|}
\hline \multirow{3}{*}{ Point } & \multicolumn{5}{|c|}{ Deflection } \\
\hline & \multirow{2}{*}{ Refined model (mm) } & \multicolumn{2}{|c|}{ General model } & \multicolumn{2}{|c|}{ Average value of the experiment } \\
\hline & & Result (mm) & Error & Result (mm) & Error \\
\hline Point A & 1.109 & 1.208 & 8.94 & 1.167 & 5.19 \\
\hline Point B & 1.673 & 1.726 & 3.15 & 1.731 & 3.47 \\
\hline Point $\mathrm{C}$ & 2.014 & 2.010 & 0.20 & 1.953 & 3.00 \\
\hline Point D & 1.671 & 1.726 & 3.27 & 1.701 & 1.77 \\
\hline Point E & 1.109 & 1.208 & 8.94 & 1.169 & 5.43 \\
\hline
\end{tabular}

TABle 4: Comparison of the stresses between the experiment and FE models.

\begin{tabular}{|c|c|c|c|c|c|}
\hline \multirow{3}{*}{ Point } & \multicolumn{5}{|c|}{ Stress } \\
\hline & \multirow{2}{*}{ Refined model (mm) } & \multicolumn{2}{|c|}{ General model } & \multicolumn{2}{|c|}{ Average value of the experiment } \\
\hline & & Result $\left(\mathrm{N} / \mathrm{mm}^{2}\right)$ & Error & Result $\left(\mathrm{N} / \mathrm{mm}^{2}\right)$ & Error \\
\hline Point 1 (top) & -25.68 & -23.22 & 9.57 & -25.37 & 1.23 \\
\hline Point 2 (top) & -26.60 & -25.36 & 4.68 & -28.20 & 5.98 \\
\hline Point 3 (top) & -26.49 & -25.36 & 4.28 & -29.97 & 13.10 \\
\hline Point 4 (top) & -26.78 & -23.22 & 13.30 & -29.43 & 9.88 \\
\hline Point 1 (bottom) & 31.19 & 29.66 & 4.92 & 30.55 & 2.08 \\
\hline Point 2 (bottom) & 52.80 & 53.71 & 1.72 & 52.95 & 0.28 \\
\hline Point 3 (bottom) & 52.80 & 53.71 & 1.71 & 52.45 & 0.68 \\
\hline Point 4 (bottom) & 31.59 & 29.66 & 6.10 & 33.47 & 5.93 \\
\hline
\end{tabular}

Tables 3 and 4 summarize the comparisons of deflection and stress between the experiment and FE models. The maximum error of deflection between the two types of FE models is $8.94 \%$ and is located at points $\mathrm{A}$ and $\mathrm{E}$. The error of deflection between the refined model and the experiment is within 5.5\%. Furthermore, the error of stress between the two models and experiment is nearly less than $10 \%$.

Overall, the results between the numerical simulation and the experiment are consistent. By contrast, the refined model has high accuracy, which is consistent with the experimental results. When the requirement of accuracy is not too strict, the general model is preferred, given modeling convenience and high efficiency.

\subsection{Three-Span Continuous Formwork}

4.3.1. FE Analysis Result. Similar to the results of the single-span simply supported formwork, both models for the three-span continuous formwork are consistent in terms of deformation shapes and stress distributions.

The deflection contours of the template (Figure 25) exhibit that extremes appear in the middle of the two side spans, thus accounting for 1.277 and $1.322 \mathrm{~mm}$ (Figures 25(a) and 25(b), correspondingly). Figure 26 displays that the extreme values appear in the middle of the side span. The longitudinal middle beams deform more clearly than the longitudinal side beams because they bear additional loads.

In Figure 27, the extreme values of longitudinal stress appear in the middle of each span and on top of the support because the maximum positive moments are located in the middle of the span, and the minimum negative moments are located on top of the support. Accordingly, the maximum longitudinal stresses of the two models (90.96 and $\left.81.00 \mathrm{~N} / \mathrm{mm}^{2}\right)$ are within the limit $\left(200 \mathrm{~N} / \mathrm{mm}^{2}\right)$.

4.3.2. Comparison of the FE Analysis and Experimental Results. Figures 28 and 29 illustrate the comparisons between the experimental and FE results. The prediction of FE is consistent with the corresponding experimental result, thus indicating that the proposed FE models can reflect the mechanical behavior of formworks well.

Table 5 lists that the maximum error between the first model and the experiment is located at point A with $6.1 \%$, thus denoting that the refined model can reflect the mechanical properties of formworks well. Moreover, the error between the two FE models is less than 6\%. Table 6 summarizes that the errors of the stresses between the two FE models and experiment are nearly less than $10 \%$.

In conclusion, the two proposed FE models can reflect the mechanical behavior of formworks well, and the refined model is more accurate than the general model. Similarly, when the requirement of accuracy is not too strict, the general model is suggested.

\section{Practical Simplified Calculation Formula of the Formwork}

To quickly and conveniently predict the deflection and evaluate the mechanical properties of the formwork in engineering practice, the practical simplified calculation formula must be deduced. 

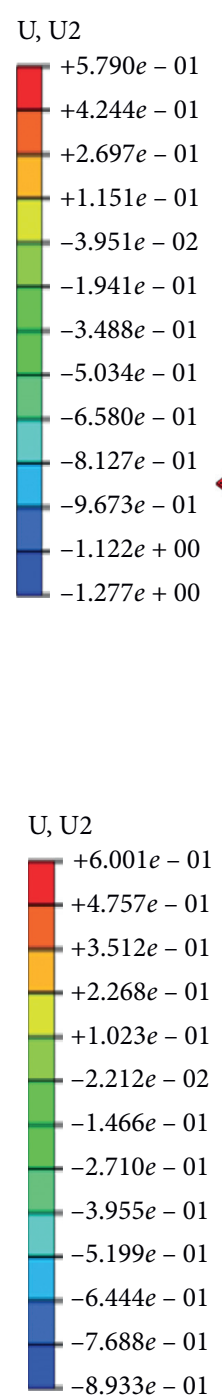

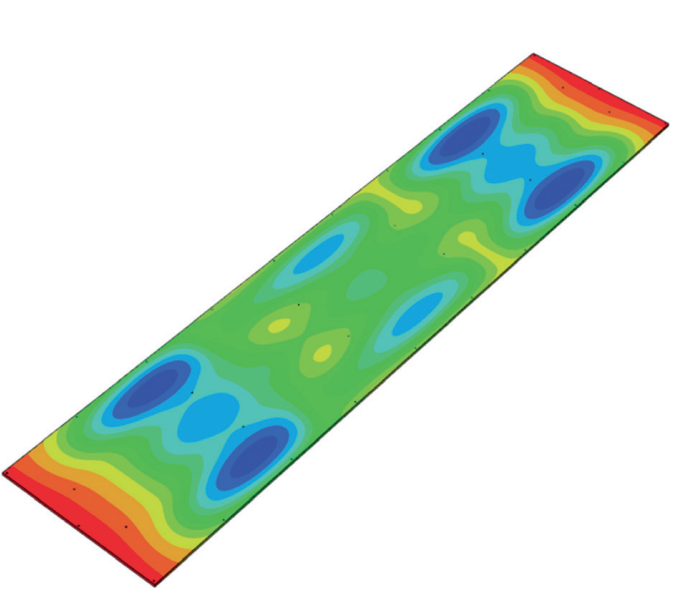

(a)

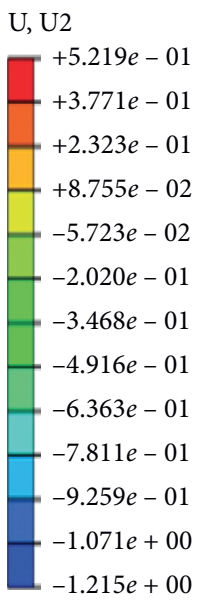

$-1.215 e+00$

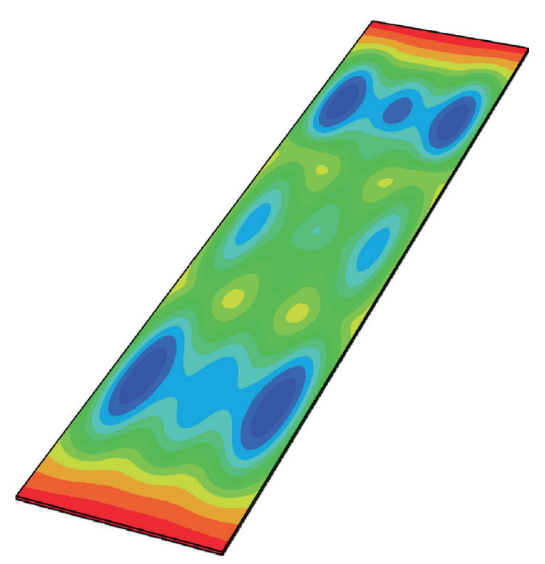

(b)

Figure 25: Deflections of the template (unit: mm). (a) Refined model. (b) General model.

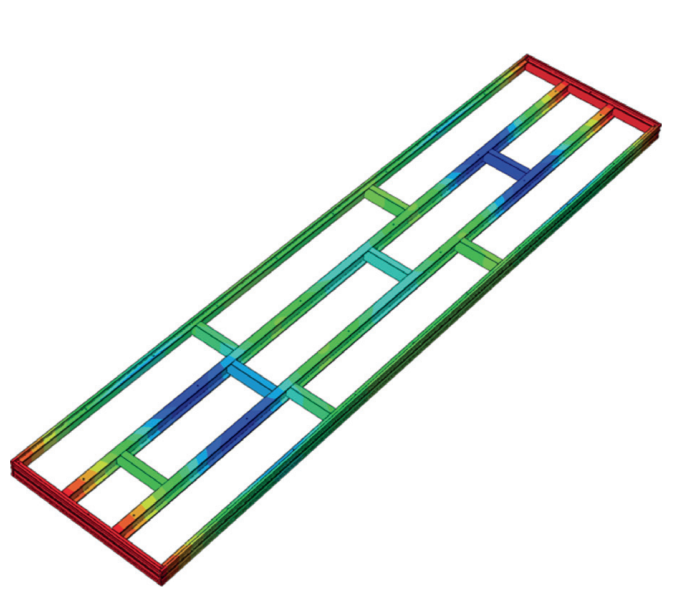

(a)

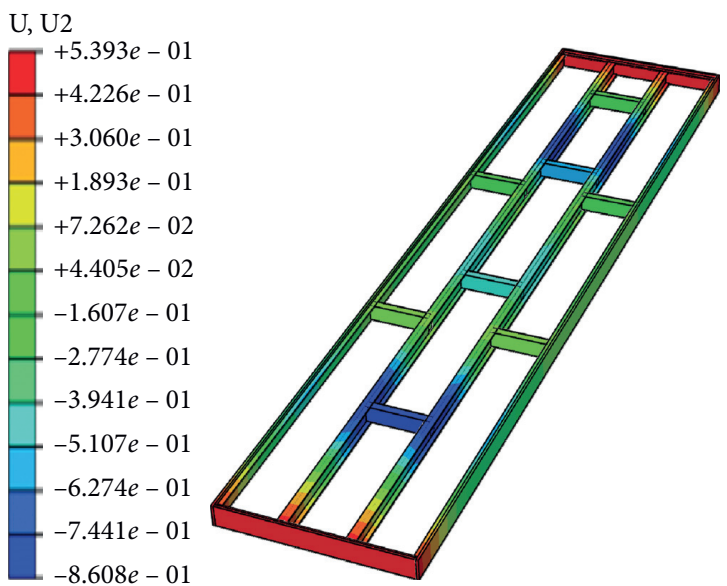

(b)

FIgURE 26: Deflections of the frame (unit: mm). (a) Refined model. (b) General model.

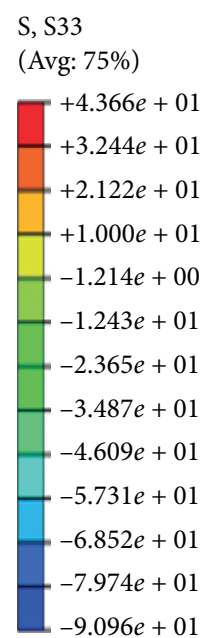

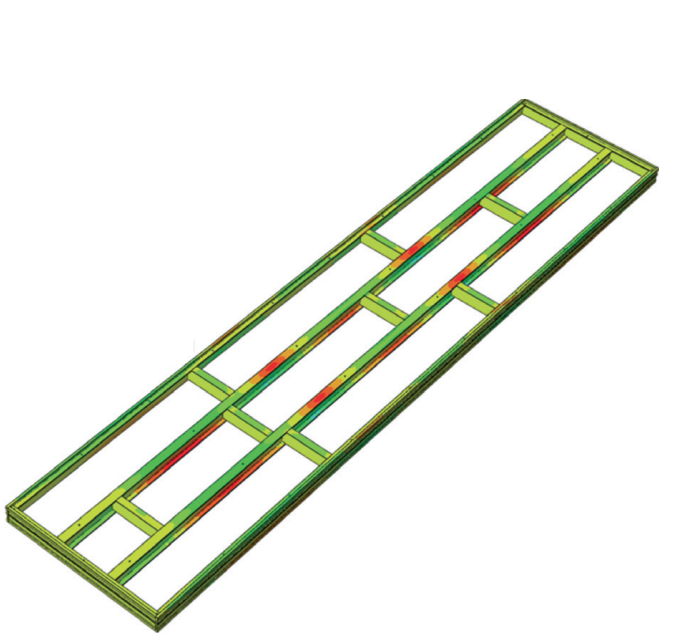

(a)
S, S33

(Avg: 75\%)

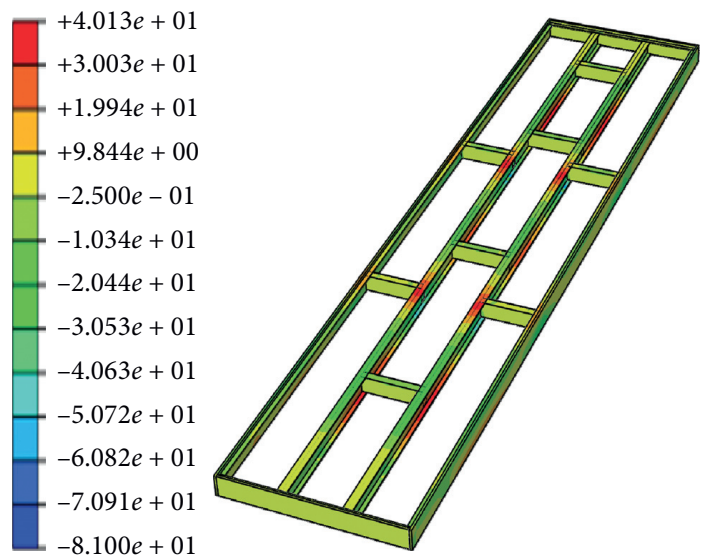

(b)

FIGURE 27: Longitudinal stresses of the frame (unit: N/mm²). (a) Refined model. (b) General model. 


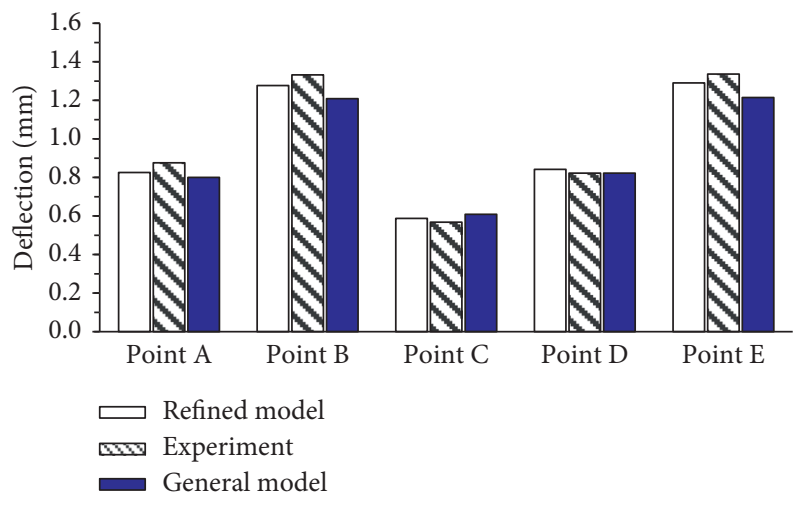

FIGURE 28: Comparison of the deflections between the experiment and FE models.

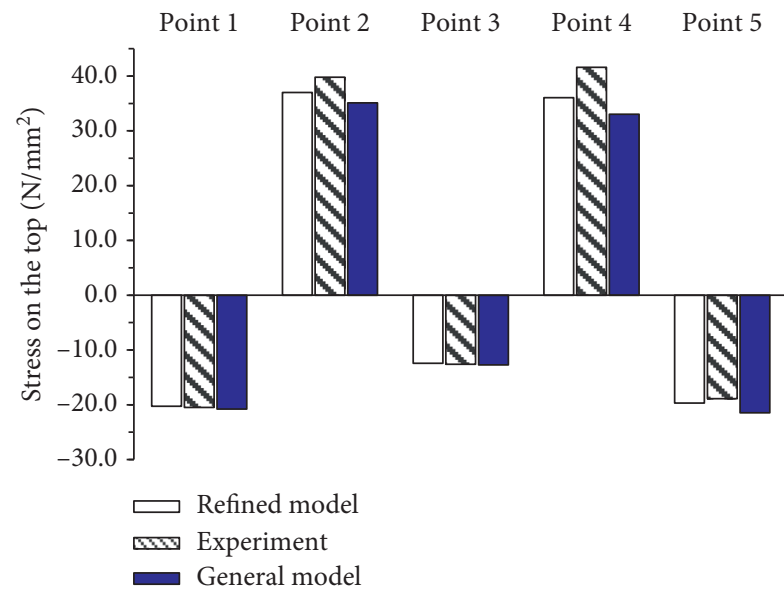

(a)

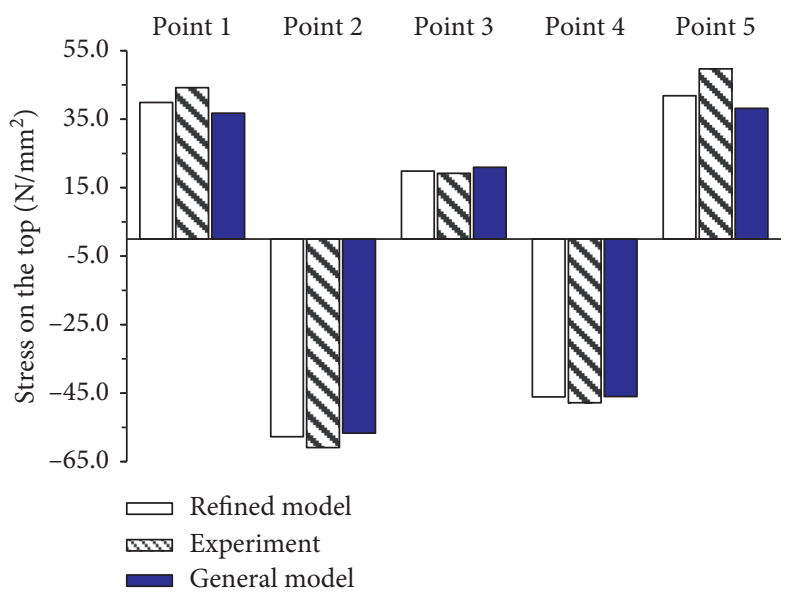

(b)

FIgure 29: Comparison of the stresses between the experiment and FE models.

TABle 5: Comparison of the deflections between the experiment and refined FE models.

\begin{tabular}{|c|c|c|c|c|c|}
\hline \multirow{3}{*}{ Point } & \multicolumn{5}{|c|}{ Deflection } \\
\hline & \multirow{2}{*}{$\begin{array}{l}\text { Refined } \\
\text { model }\end{array}$} & \multicolumn{2}{|c|}{ General model } & \multicolumn{2}{|c|}{$\begin{array}{l}\text { Average value of } \\
\text { the experiment }\end{array}$} \\
\hline & & $\begin{array}{l}\text { Result } \\
(\mathrm{mm})\end{array}$ & Error & $\begin{array}{l}\text { Result } \\
(\mathrm{mm})\end{array}$ & Error \\
\hline Point A & 0.825 & 0.800 & 3.07 & 0.876 & 6.10 \\
\hline Point B & 1.276 & 1.209 & 5.29 & 1.332 & 4.34 \\
\hline Point C & 0.587 & 0.608 & 3.56 & 0.568 & 3.32 \\
\hline Point D & 0.842 & 0.822 & 2.39 & 0.822 & 2.40 \\
\hline Point E & 1.290 & 1.215 & 5.83 & 1.336 & 3.55 \\
\hline
\end{tabular}

\subsection{Section Conversion and Cross-Sectional Geometry}

5.1.1. Section Conversion. This new composite wood-plastic formwork with an aluminum alloy frame is assembled using different materials. Two kinds of materials must be converted into the same material through formula deduction. The equivalent principles of section conversion are presented as follows:

(1) The bending stiffness is consistent before and after the section conversion

(2) The deformation of the template on the contact surface is consistent with that of the frame

Figure 30 illustrates the composite cross section of the two materials. The lower part is the aluminum alloy frame, with the whole section area $A_{f}$ and the elastic modulus of $E_{f}$. The upper part is the wood-plastic template, with the section area of $A_{w}$ and elastic modulus $E_{w}$. Figure 31 depicts the new cross section after section conversion, in which the woodplastic template is replaced by an aluminum alloy template with the cross-sectional area $A_{e}$. The detailed deduction process of the section conversion is demonstrated as follows: where $\sigma_{w}$ is the stress in the wood-plastic template, $\sigma_{e}$ is the 
TABLE 6: Comparison of the stresses between the experiment and FE models.

\begin{tabular}{|c|c|c|c|c|c|}
\hline \multirow{3}{*}{ Point } & \multirow{3}{*}{ Refined model } & \multicolumn{3}{|c|}{ Stress } & \\
\hline & & \multicolumn{2}{|c|}{ General model } & \multicolumn{2}{|c|}{ Average value of the experiment } \\
\hline & & Result $\left(\mathrm{N} / \mathrm{mm}^{2}\right)$ & Error & Result $\left(\mathrm{N} / \mathrm{mm}^{2}\right)$ & Error $(\%)$ \\
\hline Point 1 (top) & -20.26 & -20.77 & 2.51 & -20.50 & 1.14 \\
\hline Point 2 (top) & 37.01 & 35.11 & 5.13 & 39.80 & 7.54 \\
\hline Point 3 (top) & -12.41 & -12.71 & 2.41 & -12.60 & 1.50 \\
\hline Point 4 (top) & 36.06 & 33.03 & 8.38 & 41.60 & 15.36 \\
\hline Point 5 (top) & -19.68 & -21.47 & 9.07 & -18.90 & 4.00 \\
\hline Point 1 (bottom) & 39.86 & 36.73 & 7.86 & 44.20 & 10.86 \\
\hline Point 2 (bottom) & -57.76 & -56.68 & 1.86 & -60.90 & 5.44 \\
\hline Point 3 (bottom) & 19.84 & 20.96 & 5.63 & 19.20 & 3.26 \\
\hline Point 4 (bottom) & -46.10 & -46.02 & 0.17 & -47.80 & 3.67 \\
\hline Point 5 (bottom) & 41.86 & 38.16 & 8.83 & 49.70 & 18.71 \\
\hline
\end{tabular}

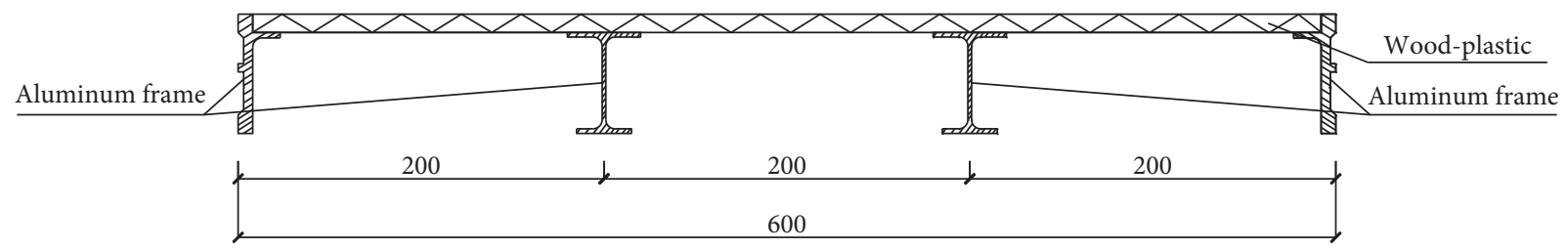

Figure 30: Actual cross section of the formwork.

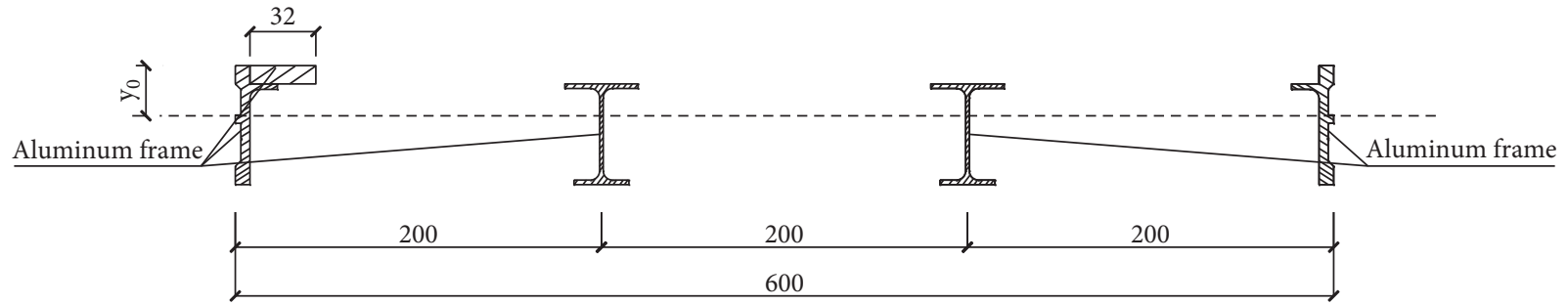

FIgURE 31: Equivalent cross section of the formwork.

stress in the equivalent template, and $\varepsilon$ is the strain in the template.

$$
\begin{aligned}
A_{w} \cdot \sigma_{w} & =A_{e} \cdot \sigma_{e}, \\
A_{e} & =\frac{\sigma_{w}}{\sigma_{e}} \cdot A_{w}, \\
\because \sigma_{e} & =E_{f} \cdot \varepsilon, \sigma_{w}=E_{w} \cdot \varepsilon, \\
A_{e} & =\frac{E_{w}}{E_{f}} \cdot A_{w},
\end{aligned}
$$

If

$$
\frac{E_{f}}{E_{w}}=n,
$$

then

$$
A_{e}=\frac{1}{n} \cdot A_{w}
$$

The sectional height remains unchanged, and only the width is changed, that is,

$$
b_{e}=\frac{1}{n} \cdot b_{w}
$$

The physical meaning of equation (4) is that the width $b_{w}$ of the wood-plastic template is divided by the ratio $n$ of the elastic modulus of the aluminum alloy and the wood-plastic material. Therefore, the equivalent width $b_{e}$ and area $A_{e}$ of the template are expressed as follows:

$$
\begin{aligned}
n & =\frac{E_{f}}{E_{w}}=\frac{0.7 \times 10^{5}}{3.84 \times 10^{3}}=18.23, \\
b_{e} & =\frac{b_{w}}{n}=\frac{58.4}{18.23}=3.2 \mathrm{~cm}, \\
A_{e} & =3.2 \times 1=3.2 \mathrm{~cm}^{2} .
\end{aligned}
$$

5.1.2. Calculation of the Cross-Sectional Geometric Properties. The cross-sectional geometries of the longitudinal beams of the frame are presented in Table 7. 
TABLE 7: Cross-sectional geometry of the longitudinal beams of the frame.

\begin{tabular}{|c|c|c|c|}
\hline \multirow{2}{*}{ Shape } & \multicolumn{3}{|c|}{ Parameter } \\
\hline & Area $\left(\mathrm{cm}^{2}\right)$ & Distance between top and centroid $(\mathrm{cm})$ & Moment of inertia $\left(\mathrm{cm}^{4}\right)$ \\
\hline 5 & 4.58 & 3.01 & 18.38 \\
\hline & 2.97 & 2.53 & 15.27 \\
\hline
\end{tabular}

The distance from the neutral axis to the top surface of the equivalent section is as follows:

$$
y_{0}=\frac{4.58 \times 3.01 \times 2+2.97 \times 3.53 \times 2+3.20 \times 0.5}{4.58 \times 2+2.97 \times 2+3.20}=2.74 \mathrm{~cm} \text {. }
$$

The conversion moment of the inertia of the equivalent section is as follows:

$$
\begin{aligned}
I_{e}= & {\left[18.38+4.58 \times(3.01-2.74)^{2}\right] \times 2 } \\
& +\left[15.27+2.97 \times(3.53-2.74)^{2}\right] \times 2+3.20 \\
& \times(2.74-0.05)^{2} \\
= & 37.43+34.25+23.16 \\
= & 94.84 \mathrm{~cm}^{2} .
\end{aligned}
$$

\subsection{Single-Span Simply Supported Formwork}

5.2.1. Calculation of Deflection. According to structural mechanics, the formula for calculating the maximum deflection of simply supported beams is as follows:

$$
f_{\max }=\frac{5}{384} \times \frac{q l^{4}}{E I} .
$$

The actual deflection is larger than the calculated deflection value because the composite formwork is incompletely integrated. To make the calculated deflection value reflect the actual deformation, the stiffness is suggested to be multiplied by the reduction factor $\eta_{1}[20]$, and the maximum deflection value is revised as follows:

$$
f_{\max }=\frac{5}{384} \times \frac{q l^{4} b}{E I} \times \frac{1}{\eta}
$$

where $b$ is the width of the template. The maximum deflection of the template is as follows:

$$
\begin{aligned}
f_{\max 1}= & \frac{5}{384} \times \frac{q l^{4} b}{E I} \times \frac{1}{\eta}=\frac{5}{384} \times \frac{0.015 \times 900^{4} \times(600-8-8)}{0.7 \times 10^{5} \times 94.84 \times 10^{4}} \\
& \times \frac{1}{\eta}=\frac{1.1273}{\eta} \mathrm{mm} .
\end{aligned}
$$

The abovementioned calculation assumes that the formwork is simplified as a beam. In comparison with the frame, the template has a relative deflection in a transverse direction:

$$
f_{\max 2}=\frac{5}{384} \times \frac{q l^{4} b}{E I}=\frac{5}{384} \times \frac{0.015 \times(200-40)^{4} \times 500}{3.84 \times 10^{3} \times\left(\left(500 \times 10^{3}\right) / 12\right)}=0.4 \mathrm{~mm} .
$$

Thus, the total maximum deflection of formwork is as follows:

$$
f_{\max 1}+f_{\max 2}=\left(\frac{1.1273}{\eta}+0.4\right) \mathrm{mm}
$$

5.2.2. Stiffness Reduction Factor. The FE analysis results of the refined model are substituted into the total maximum deflection calculation formula as follows:

$$
\frac{1.1273}{\eta_{1}}+0.4=2.014
$$

The equation is solved, and the stiffness reduction factor $\eta_{1}=0.70$ is obtained.

\subsection{Three-Span Continuous Formwork}

5.3.1. Calculation of the Deflection. According to structural mechanics, the formula for calculating the maximum deflection of the three-span continuous beam is as follows: 
TABLE 8: Comparison of the deflection of different stiffness reduction factors for the single-span simply supported formwork.

\begin{tabular}{|c|c|c|c|c|c|c|c|c|}
\hline Load (k & & 1.5585 & 2.3385 & 3.5070 & 5.2605 & 7.8915 & 11.8365 & 15.0000 \\
\hline Analysis & ue of the refined model (mm) & 0.2076 & 0.3109 & 0.4661 & 0.6989 & 1.0480 & 1.5740 & 2.0140 \\
\hline & Simplified calculation value $(\mathrm{mm})$ & 0.2217 & 0.3327 & 0.4990 & 0.7485 & 1.1228 & 1.6841 & 2.1342 \\
\hline$\eta=0.65$ & Error & $6.81 \%$ & $7.02 \%$ & $7.06 \%$ & $7.09 \%$ & $7.14 \%$ & $7.00 \%$ & $5.97 \%$ \\
\hline & Simplified calculation value $(\mathrm{mm})$ & 0.2190 & 0.3286 & 0.4928 & 0.7393 & 1.1090 & 1.6634 & 2.1080 \\
\hline$\eta=0.60$ & Error & $5.50 \%$ & $5.70 \%$ & $5.74 \%$ & $5.78 \%$ & $5.82 \%$ & $5.68 \%$ & $4.67 \%$ \\
\hline & Simplified calculation value $(\mathrm{mm})$ & 0.2164 & 0.3247 & 0.4869 & 0.7303 & 1.0956 & 1.6433 & 2.0825 \\
\hline 0.67 & Error & $4.22 \%$ & $4.43 \%$ & $4.46 \%$ & $4.50 \%$ & $4.54 \%$ & $4.40 \%$ & $3.40 \%$ \\
\hline & Simplified calculation value $(\mathrm{mm})$ & 0.2138 & 0.3208 & 0.4811 & 0.7216 & 1.0826 & 1.6238 & 2.0577 \\
\hline & Error & $2.99 \%$ & $3.18 \%$ & $3.22 \%$ & $3.25 \%$ & $3.30 \%$ & $3.16 \%$ & $2.17 \%$ \\
\hline & Simplified calculation value $(\mathrm{mm})$ & 0.2113 & 0.3171 & 0.4755 & 0.7132 & 1.0699 & 1.6048 & 2.0337 \\
\hline$\eta=$ & Error & $1.78 \%$ & $1.98 \%$ & $2.01 \%$ & $2.05 \%$ & $2.09 \%$ & $1.96 \%$ & $0.98 \%$ \\
\hline & Simplified calculation value $(\mathrm{mm})$ & 0.2089 & 0.3134 & 0.4700 & 0.7050 & 1.0577 & 1.5864 & 2.0104 \\
\hline & Error & $0.62 \%$ & $0.81 \%$ & $0.84 \%$ & $0.88 \%$ & $0.92 \%$ & $0.79 \%$ & $0.18 \%$ \\
\hline
\end{tabular}

TABle 9: Comparison of the deflections of different stiffness reduction factors for the three-span continuous formwork.

\begin{tabular}{|c|c|c|c|c|c|c|c|}
\hline \multicolumn{2}{|c|}{ Load $\left(\mathrm{kN} / \mathrm{m}^{2}\right)$} & 3.0000 & 6.0000 & 10.5000 & 17.2500 & 27.3750 & 30.0000 \\
\hline \multicolumn{2}{|c|}{ Analysis value of the refined model (mm) } & 0.1349 & 0.2610 & 0.4521 & 0.7373 & 1.1650 & 1.2770 \\
\hline \multirow{2}{*}{$\eta=0.65$} & Simplified calculation value (mm) & 0.1286 & 0.2571 & 0.4500 & 0.7392 & 1.1731 & 1.2856 \\
\hline & Error & $4.70 \%$ & $1.48 \%$ & $0.47 \%$ & $0.26 \%$ & $0.70 \%$ & $0.68 \%$ \\
\hline \multirow{2}{*}{$\eta=0.66$} & Simplified calculation value (mm) & 0.1272 & 0.2545 & 0.4454 & 0.7317 & 1.1611 & 1.2725 \\
\hline & Error & $5.67 \%$ & $2.49 \%$ & $1.49 \%$ & $0.76 \%$ & $0.33 \%$ & $0.36 \%$ \\
\hline \multirow[b]{2}{*}{$\eta=0.67$} & Simplified calculation value (mm) & 0.1260 & 0.2519 & 0.4409 & 0.7243 & 1.1495 & 1.2597 \\
\hline & Error & $6.62 \%$ & $3.47 \%$ & $2.48 \%$ & $1.76 \%$ & $1.33 \%$ & $1.36 \%$ \\
\hline \multirow{2}{*}{$\eta=0.68$} & Simplified calculation value (mm) & 0.1247 & 0.2495 & 0.4365 & 0.7172 & 1.1381 & 1.2473 \\
\hline & Error & $7.54 \%$ & $4.42 \%$ & $3.44 \%$ & $2.73 \%$ & $2.31 \%$ & $2.33 \%$ \\
\hline \multirow{2}{*}{$\eta=0.69$} & Simplified calculation value (mm) & 0.1235 & 0.2470 & 0.4323 & 0.7103 & 1.1271 & 1.2352 \\
\hline & Error & $8.43 \%$ & $5.35 \%$ & $4.37 \%$ & $3.67 \%$ & $3.25 \%$ & $3.27 \%$ \\
\hline \multirow{2}{*}{$\eta=0.7$} & Simplified calculation value (mm) & 0.1224 & 0.2447 & 0.4282 & 0.7035 & 1.1165 & 1.2235 \\
\hline & Error & $9.30 \%$ & $6.24 \%$ & $5.28 \%$ & $4.58 \%$ & $4.17 \%$ & $4.19 \%$ \\
\hline
\end{tabular}

$$
f_{\max }=6.77 \times 10^{-3} \times \frac{q l^{4}}{E I}
$$

As mentioned in Section 5.2, the stiffness must be revised by the reduction factor $\eta_{2}$ :

$$
f_{\max }=6.77 \times 10^{-3} \times \frac{q l^{4}}{E I} \times \frac{1}{\eta} .
$$

The maximum deflection of the formwork is as follows:

$$
\begin{aligned}
f_{\max 1}= & 6.77 \times 10^{-3} \times \frac{q l^{4} b}{E I} \times \frac{1}{\eta}=6.77 \times 10^{-3} \\
& \times \frac{0.03 \times 750^{4} \times 584}{0.7 \times 10^{5} \times 94.84 \times 10^{4}} \times \frac{1}{\eta}=\frac{0.5653}{\eta} \mathrm{mm} .
\end{aligned}
$$

In the transverse direction, the formwork has a relative deflection. The difference between the transverse spans of the three continuous formworks is within 5\%. Therefore, the formwork is simplified as an equal-span structure:

$$
\begin{aligned}
f_{\max 2}= & 6.77 \times 10^{-3} \times \frac{q l^{4} b}{E I}=6.77 \times 10^{-3} \\
& \times \frac{0.03 \times 160^{4} \times 750}{3.84 \times 10^{3} \times\left(\left(750 \times 10^{3}\right) / 12\right)}=0.41 \mathrm{~mm} .
\end{aligned}
$$

Thus, the total maximum deflection of formwork is as follows:

$$
f_{\max 1}+f_{\max 2}=\left(\frac{0.5653}{\eta}+0.41\right) \mathrm{mm} .
$$

The FE analysis results are substituted to the total maximum deflection calculation formula as follows:

$$
\frac{0.5653}{\eta_{2}}+0.41=1.277
$$


The stiffness reduction factor $\eta_{2}=0.65$ can be obtained.

5.4. Determination of a Unified Stiffness Reduction Factor. Tables 8 and 9 summarize the comparisons of the different stiffness reduction factors ( 0.65 to 0.70 according to Sections 5.2.2 and 5.3.1) for the single-span simply supported and three-span continuous formworks.

When $\eta=0.67$, nearly all errors are less than $5 \%$. Therefore, the unified stiffness reduction factor for the two types of the formworks is 0.67 .

5.5. Practical Simplified Calculation Formula. The practical simplified calculation formulas of the single-span simple supported and three-span continuous formworks are expressed as follows:

$$
\begin{aligned}
& f_{\text {max }}=\frac{5}{384} \times \frac{q l_{1}^{4} b_{1}}{E_{f} I_{e}} \times \frac{1}{0.67}+\frac{5}{384} \times \frac{q l_{2}^{4} b_{2}}{E_{w} I_{w}}, \\
& f_{\text {max }}=6.77 \times 10^{-3} \times \frac{q l_{1}^{4} b_{1}}{E_{f} I_{e}} \times \frac{1}{0.67}+6.77 \times 10^{-3} \times \frac{q l_{2}^{4} b_{2}}{E_{w} I_{w}},
\end{aligned}
$$

where $q$ is the load, $l_{1}$ is the longitudinal span of the frame, $l_{2}$ is the transverse length of the frame under loading, $b_{1}$ is the transverse span of the formwork, $b_{2}$ is the longitudinal length of the formwork under loading, $E_{f}$ is the elastic module of the frame, $E_{w}$ is the elastic module of the formwork, $I_{e}$ is the conversion moment of the inertia of the section, and $I_{w}$ is the conversion moment of the inertia of the formwork.

\section{Conclusion}

(1) During the loading process of the experiments, the deflections and stresses of the formworks increase linearly, and the test deflections and stresses are within the allowable values under the maximum experimental loads. Therefore, the new composite wood-plastic formworks perform well and can satisfy the structural bearing requirements.

(2) Numerical analyses confirm that the experimental considerations are accurate. The calculated values of the deflection and stress of the two FE models (refined and general) agree with the experimental results. Moreover, the general model can replace the refined model to simplify the problem when the accuracy requirement is not too strict.

(3) On the basis of the theoretical analysis and experimental research, the practical simplified formulas are proposed to facilitate the rapid calculation and evaluation for engineers considering the transverse deflection and inconsistency of two materials.

\section{Data Availability}

Some or all data, models, or code that support the findings of this study are available from the corresponding author upon reasonable request.

\section{Consent}

Informed consent was obtained from all individual participants included in the study.

\section{Disclosure}

This article does not contain any studies with human participants or animals performed by any of the authors.

\section{Conflicts of Interest}

The authors declare that there are no conflicts of interest regarding the publication of this article.

\section{Acknowledgments}

This study was supported by the Opening Project of the State Key Laboratory of Subtropical Building Science, South China University of Technology, China (Grant no. 2019ZB27), and the Science and Technology Program of Guangzhou, China (Grant no. 1563000257).

\section{References}

[1] B. J. Lee and Y. Y. Yun, "Durability of latex modified concrete mixed with a shrinkage reducing agent for bridge deck pavement," International Journal of Concrete Structures and Materials, vol. 12, no. 2, pp. 259-267, 2018.

[2] S. Q. Ruan and C. Unluer, "Comparison of the environmental impacts of reactive magnesia and calcined dolomite and their performance under different curing conditions," Journal of Materials in Civil Engineering, vol. 30, no. 11, Article ID 04018279, 2018.

[3] R. Gagné, E. Houehanou, M. Jolin, and P. Escaffit, "Study of the relationship between scaling resistance and sorptivity of concrete," Canadian Journal of Civil Engineering, vol. 38, no. 11, pp. 1238-1248, 2011.

[4] Y. Wei, Z. H. Wu, J. S. Huang, and S. M. Liang, "Comparison of compressive, tensile, and flexural creep of early-age concretes under sealed and drying conditions," Journal of Materials in Civil Engineering, vol. 30, no. 11, Article ID 04018289, 2018.

[5] A. F. Omran and K. H. Khayat, "Effect of formwork characteristics on SCC lateral pressure," Journal of Materials in Civil Engineering, vol. 29, no. 5, Article ID 04016293, 2017.

[6] E. E. Elbeltagi, O. A. Hosny, A. Elhakeem, M. E. Abdelrazek, and M. S. El-Abbasy, "Fuzzy logic model for selection of vertical formwork systems," Journal of Construction Engineering and Management, vol. 138, no. 7, pp. 832-840, 2012.

[7] S. Tichko, G. De Schutter, P. Troch et al., "Influence of the viscosity of self-compacting concrete and the presence of rebars on the formwork pressure while filling bottom-up," Engineering Structures, vol. 101, pp. 698-714, 2015.

[8] C. M. Tam, T. K. L. Tong, C. T. Tony, T. C. T. Lau, and K. K. Chan, "Selection of vertical formwork system by 
probabilistic neural networks models," Construction Management and Economics, vol. 23, no. 3, pp. 245-254, 2005.

[9] A. S. Hanna and A. B. Senouci, "Neuroslab-neural network system for horizontal formwork selection," Canadian Journal of Civil Engineering, vol. 22, no. 22, pp. 785-792, 2011.

[10] J. Nikhil and M. S. V. Z. Patil, "Comparative study of various vertical formwork systems and preparation of formwork selection model using fuzzy logic," International Journal of Scientific Research, vol. 4, no. 7, pp. 184-186, 2015.

[11] E. Martinez, I. Tommelein, and A. Alvear, "Formwork system selection using choosing by advantages," in Proceedings of Construction Research Congress, pp. 1700-1709, San Juan, Puerto Rico, May 2016.

[12] W. N. Meng, K. H. Khayat, and Y. Bao, "Flexural behaviors of fiber-reinforced polymer fabric reinforced ultra-high-performance concrete panels," Cement and Concrete Composites, vol. 93, pp. 44-53, 2018.

[13] J. Carrillo, F. Riveros, and L. Llano, "Development and testing of a novel steel formwork for casting concrete slabs with different sizes," Facultad de Ingeniería, vol. 26, no. 46, pp. 51-59, 2017.

[14] E. Gallego, J. M. Fuentes, A. Ramírez, and F. Ayuga, "Computer simulation of complex-shaped formworks using three-dimensional numerical models," Automation in Construction, vol. 20, no. 7, pp. 830-836, 2011.

[15] S. Wang, H. J. Liu, and L. Sun, "Analysis on problems of design calculation for flexible assembly plywood formwork," Journal of Qingdao Technological University, vol. 35, no. 2, pp. 123-129, 2014.

[16] J. Wang, J. Zhang, X. Ding, and J. Zhang, "Effect of cementitious permanent formwork on moisture field of internal-cured concrete under drying," Mechanics of Time-dependent Materials, vol. 22, no. 1, pp. 95-127, 2018.

[17] E. Gallego, J. M. Fuentes, A. Ramírez, and F. Ayuga, "Design of tall formworks by a finite-element model," Journal of Construction Engineering and Management, vol. 136, no. 7, pp. 803-810, 2010.

[18] JGJ162, Technical Code for Safety of Forms in Construction, Chinese Standard, Beijing, China, 2008.

[19] S. Alimirzaei, M. Mohammadimehr, and A. Tounsi, "Nonlinear analysis of viscoelastic micro-composite beam with geometrical imperfection using FEM: MSGT electro-magneto-elastic bending," Buckling and Vibration Solutions, vol. 71, no. 5, pp. 485-502, 2019.

[20] X. J. Li, Study and Application of New Type Architecture Mode, MA. Dissertation, Zhejiang University, Hangzhou, China, 2003. 